\title{
Involvement of CRH Receptors in the Neuroprotective Action of R-Apomorphine in the Striatal 6-OHDA Rat Model
}

\author{
Mustafa $\operatorname{Varçin}^{1}$, Eduard Bentea ${ }^{1}$, Steven Roosens ${ }^{1}$, Yvette Michotte $^{1}$, Sophie Sarre ${ }^{1,2^{*}}$ \\ ${ }^{1}$ Department of Pharmaceutical Chemistry and Drug Analysis, Center for Neurosciences, Vrije Universiteit Brussel, Faculty of \\ Medicine and Pharmacy, Brussels, Belgium; ${ }^{2}$ Belgian Pharmacists Association, Medicines Control Laboratory, Brussels, Belgium. \\ Email: *Sophie.Sarre@apb.be
}

Received October $21^{\text {st }}, 2013$; revised November $20^{\text {th }}, 2013$; accepted December $10^{\text {th }}, 2013$

Copyright (C) 2013 Mustafa Varçin et al. This is an open access article distributed under the Creative Commons Attribution License, which permits unrestricted use, distribution, and reproduction in any medium, provided the original work is properly cited.

\begin{abstract}
The dopamine D1-D2 receptor agonist, R-apomorphine, has been shown to be neuroprotective in different models of Parkinson's disease. Different mechanisms of action for this effect have been proposed, but not verified in the striatal 6-hydroxydopamine rat model. In this study, the expression of a set of genes involved in 1) signaling, 2) growth and differentiation, 3) neuronal regeneration and survival, 4) apoptosis and 5) inflammation in the striatum was measured after a subchronic R-apomorphine treatment $(10 \mathrm{mg} / \mathrm{kg}$ /day, subcutaneously, during 11 days $)$ in the striatal 6-hydroxydopamine rat model. The expression of 84 genes was analysed by using the rat neurotrophins and receptors RT $^{2}$ Profiler ${ }^{\mathrm{TM}}$ PCR array. The neuroprotective effects of R-apomorphine in the striatal 6-hydroxydopamine model were confirmed by neurochemical and behavioural analysis. The expression data suggest the observed neuroprotection involved the alteration of the gene and the protein expression levels of the anti-inflammatory corticotropin releasing hormone receptor (CRHR) 1 and the pro-inflammatory CRHR2 receptor confirming its potential anti-inflammatory action.
\end{abstract}

Keywords: Apomorphine; Gene Expression; Inflammation; Neuroprotection; Parkinson's Disease; Striatal 6-Hydroxydopamine Rat Model

\section{Introduction}

Until today, the available treatments for Parkinson's disease do not stop or slow down the progressive nature of the disease and are based on dopamine (DA) replacement strategies, such as the use of DA agonists and/or the DA precursor, levodopa (L-DOPA) [1]. Due to the long presymptomatic phase of the disease, therapeutic intervenetions that result in the protection, restoration and/or rescuing of the dopaminergic neurons are of extreme importance to improve the quality of life of the patients $[1,2]$.

Although R-apomorphine has been introduced as a drug a certain time ago, it is still available as treatment for patients with Parkinson's disease and with advanced Parkinson's disease and for the treatment of persistent and disabling motor fluctuations which do not respond to

${ }^{*}$ Corresponding author.
L-DOPA [3-7]. It activates D1-like (D1, D5) and D2-like (D2, D3, D4) receptors, serotonin receptors (5HT1A, 5HT2A, 5HT2B and 5HT2C) and $\alpha$-adrenergic receptors $(\alpha 1 \mathrm{~B}, \alpha 1 \mathrm{D}, \alpha 2 \mathrm{~A}, \alpha 2 \mathrm{~B}, \alpha 2 \mathrm{C})[8]$.

$\mathrm{R}$-apomorphine has been shown to be neuroprotective both in vitro and in vivo, including the 1-methyl-4-phenyl1,2,3,6-tetrahydropyridine (MPTP) [9-12], 6-hydroxydopamine (6-OHDA) [13-15] and methamphetamine (METH) $[12,16]$ rodent models of Parkinson's disease and more recently, a mouse model of Alzheimer's disease [17]. The in vivo neuroprotective properties of $\mathrm{R}$ apomorphine have been shown to be dose dependent, and mainly linked to the administration of high doses of Rapomorphine. These findings also suggest that the neuroprotective action may involve other pathways rather than activation of DA receptors. Among the proposed mechanisms of action are its radical scavenging activity $[13,15,18,19]$ and iron chelating properties [20], inhibi- 
tion of mitochondrial iron-induced lipid peroxidation and protein oxidation $[13,18,19]$, activation of nuclear transcription factor NF-E2-related factor 2 (Nrf2) [21], inhibition of monoamine oxidase (MAO)-A and MAO-B [22], its enhancement of glutathione peroxidase activity [23], anti-apoptotic [7,24], anti-inflammatory [9], mitogenic [25] and trophic effects [26-29]. We previously showed that a short-term treatment with R-apomorphine $(10 \mathrm{mg} / \mathrm{kg} /$ day, s.c., during 11 days), started before or 24 hours after lesions, has neuroprotective actions in the striatal 6-OHDA rat model, as demonstrated by an improved motor behavior and a significant protection $(20 \%$ - $35 \%$ ) of the integrity of the nigrostriatal dopaminergic system at the level of the substantia nigra pars compacta and striatum [14]. As hydroxyl radical formation is considered as an important event in the neurotoxicity of 6-OHDA [30], several in vivo studies investigated the interference of R-apomorphine with the hydroxyl radical formation in the rat striatum [13-15]. However, these findings are not consistent. Furthermore, Battaglia et al. [11] have shown that R-apomorphine is still neuroprotective after $40 \mathrm{~h}$ following MPTP injections, and together with our previous findings that R-apomorphine is still neuroprotective $24 \mathrm{~h}$ after 6-OHDA administration [14], it can be suggested that the mechanism of action of $\mathrm{R}$-apomorphine is not linked to the interference with the initial effects of the neurotoxins.

Although different mechanisms of action of R-apomorphine, as summarised above, have been proposed for its neuroprotective effect, these have not been extensively explored in the striatal 6-OHDA rat model. In this study, we screened the expression of a set of genes involved in 1) signaling, 2) growth and differentiation, 3) neuronal regeneration and survival, 4) apoptosis and 5) inflammation in the central nervous system after a subchronic R-apomorphine treatment $(10 \mathrm{mg} / \mathrm{kg} / \mathrm{day}$, s.c., during 11 days) in the unilateral striatal 6-OHDA parkinsonian rat model.

Our data confirm the neuroprotective effects of R-apo morphine in the unilateral striatal 6-OHDA parkinsonian rat model and suggest that they may involve the alteration of the striatal gene and the protein expression levels of the anti-inflammatory corticotropin releasing hormone receptor (CRHR) 1 and the pro-inflammatory CRHR2 receptor.

\section{Experimental Procedure}

All the chemical compounds where no supplier is mentioned, are supplied by Sigma-Aldrich, Brussels, Belgium.

\subsection{Animals}

In all experiments, male albino Wistar rats (Charles River, Sulzfeld, Germany) weighing 175 - 200 g were used. Animals were kept under standardised conditions $\left(25^{\circ} \mathrm{C}, 12 \mathrm{~h}\right.$ light-dark cycle) with free access to food and tap water. At the end of the experiments, rats were sacrificed with an overdose of pentobarbital (Nembutal ${ }^{\circledR}$, Ceva Sante Animale, Brussels, Belgium). Animal experiments were carried out according to the national guidelines on animal experimentation and were approved by the Ethical Committee for Animal Experiments of the Faculty of Medicine and Pharmacy of the Vrije Universiteit Brussel. All efforts were made to minimise animal suffering and the minimal number of animals necessary to produce reliable scientific data was used.

\subsection{Effects of R-Apomorphine on the Progress of Neurodegeneration in Rats Unilaterally Lesioned with 6-OHDA}

\subsubsection{Experimental Design}

The experimental design is described in Figure 1. The rats were divided into 3 groups. Rats in group I were used as non-lesioned controls, receiving subcutaneous injections of saline. Rats in groups II were injected unilaterally with $3 \mu \mathrm{l}$ of 6 -OHDA solution $(6.7 \mu \mathrm{g} / \mu \mathrm{l}$ in $0.1 \%$ ascorbic acid) in the left striatum and subcutaneously with saline. Rats in group III were lesioned with

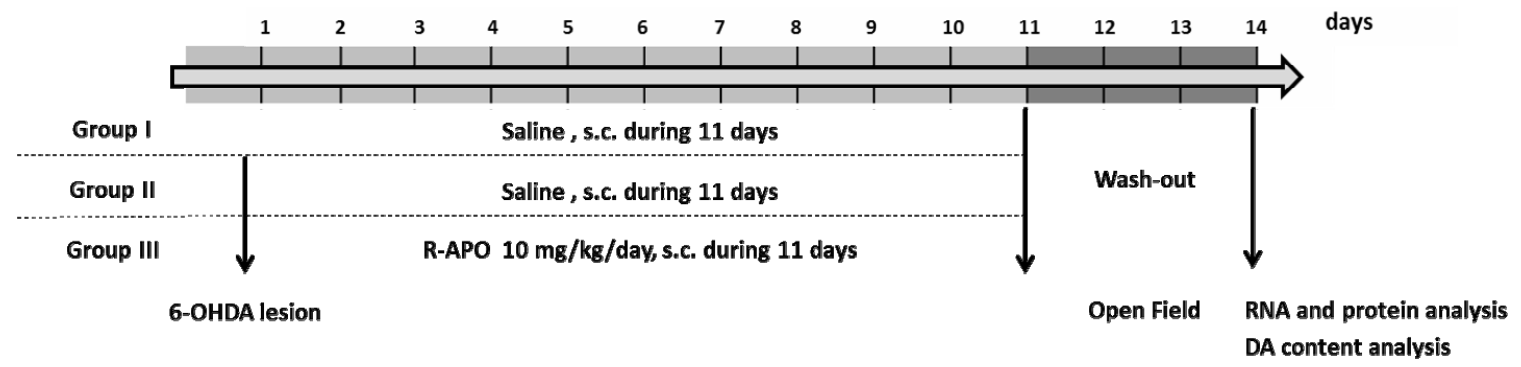

Figure 1. Experimental design. The rats were divided into 3 groups. Rats in group I were used as non-lesioned controls, rats in groups II were injected intrastriatally with 6-OHDA and subcutaneously with saline, and rats in group III were lesioned with 6-OHDA similar to rats of group II, but also received daily subcutaneous injections of R-apomorphine $(10 \mathrm{mg} / \mathrm{kg} / \mathrm{day})$. Further details are described in Materials and Methods. Abbreviations: R-APO: R-apomorphine, s.c. subcutaneously. 
6-OHDA similar to rats of group II, but also received daily subcutaneous injections of R-apomorphine $(10 \mathrm{mg} /$ $\mathrm{kg} /$ day). The treatment with R-apomorphine started 15 min before the intrastriatal injection of 6-OHDA and continued for another 10 days. The dose of the R-apomorphine was based on previous findings $[10,11,14]$. Briefly, Grünblatt et al had already demonstrated that a low dose $(0.5,1,2$, and $2.5 \mathrm{mg} / \mathrm{kg})$ of R-apomorphine does not protect against MPTP induced DA loss in mice, whereas the higher dose $(10 \mathrm{mg} / \mathrm{kg})$ restored the values to those of control mice [10]. Similar findings were reported in 2001 [22]. Furthermore, Fornai et al demonstrated a dose dependent neuroprotective effect of Rapomorphine in methamphetamine induced DA depletion. Based on these findings, we decided to use $10 \mathrm{mg} / \mathrm{kg}$ Rapomorphine in the 6-OHDA striatal rat model. Animals were visually checked at regular intervals and weighed daily before any manipulation until the end of the experiment (day 14). For all the groups there was a washout period of 3 days. Different sets of rats were used for the initial screening of the relative striatal gene expression levels on the one hand, and behavioural testing, assessment of DA and DOPAC content, and protein expression analysis on the other. mRNA of high quality was used during the gene expression studies, and therefore the purity and integrity of all mRNA samples were checked with advanced methods, such as UV spectrophotometry and a microfluidics based electrophoresis system. The specificity of the PCR reaction has been evaluated by analysing the PCR product (the amplicon) by conducting at the end of each RTqPCR experiment a melt curve analysis for each amplicon. The web based software of the company (SA Biosciences, MD) also automatically performed a quality control for each PCR run. The quality of the reference genes has been evaluated by the software program that was provided by the supplier (SA Biosciences, MD) of the PCR arrays. The selection of the potential candidate genes for the protein expression analysis was based on experimental and literature findings. To mitigate biological and technical variabilities during a gene expression study, the recommended number of biological replicates is minimum three, and for technical replicates minimum two [31]. We managed to have the minimum number of biological replicates for the gene expression study, but unfortunately technical replicates were not possible due to the limited sample volume. Despite a lower number of animals for the gene expression studies, our slightly higher number of animals for the protein expression favours our observations at the gene level.

\subsubsection{Local Administration of 6-OHDA by Striatal Stereotaxic Microinjection}

Rats were anaesthesized with a mixture of ketamine (50 mg/kg i.p.; Ketamine $1000 \mathrm{Ceva}^{\circledR}$, Ceva Sante Animale, Brussels, Belgium) and diazepam (5 mg/kg i.p.; Valium $^{\circledR}$, Roche Brussels, Belgium) and placed on a Kopf stereotaxic frame (David Kopf Instruments, Tujunga, California, USA). The skull was exposed and a burr hole was drilled to introduce a syringe for a single injection of the 6-OHDA solution [containing $6.7 \mu \mathrm{g} 6$-OHDA per $\mu 1$ in $0.1 \%$ ascorbic acid, $\mathrm{pH} 5.0]$. To minimize variability due to degradation of the toxin, the 6-OHDA solution was freshly prepared, kept on ice, and protected from exposure to light. The solution was injected in the left striatum at the following coordinates relative to the bregma $\mathrm{L}$ : $-3.0, \mathrm{~A}:+1.0$ and $\mathrm{V}:+5.0$, according to the atlas of Paxinos and Watson [32]. A total volume of $3 \mu 16$-OHDA was injected at a flow rate of $1 \mu \mathrm{l} / \mathrm{min}$. After injection, the syringe was left in place for $5 \mathrm{~min}$ and then slowly removed over a 1 - 2 min time period. The skin was sutured, the animals received ketoprofen $(4 \mathrm{mg} / \mathrm{kg}$ i.p.; Ketofen $^{\circledR}$, Merial, Brussels, Belgium) as analgesic and were allowed to recover before returning to the animal housing facilities [14].

\subsection{Behavioral Analysis}

\section{Locomotor activity in Open Field}

The spontaneous locomotor activity was monitored in a Plexiglas box (sides, $60 \mathrm{~cm}$; height, $60 \mathrm{~cm}$ ). At least $1 \mathrm{~h}$ prior to testing, rats were acclimated to the testing room. The recording started immediately after placing animals in the open field and continued for $60 \mathrm{~min}$. To neutralise odor formation, the arena was disinfected and cleaned with $70 \%$ ethanol before each rat was tested. Experiments were performed between 09:00 AM and 06:00 PM. The rat was placed carefully in the center of the arena, and allowed to explore the field for $60 \mathrm{~min}$. Each performance was automatically analysed using a video tracking system and Ethovision 3.0 tracking software (Noldus, the Netherlands). The following parameters were recorded: 1) distance moved, 2) movement time, 3) immobility, 4) velocity, 5) rearing and 6) relative meander. The assessment of spontaneous locomotor behavior was carried out during the wash-out period of the proto$\mathrm{col}$, in order to avoid a possible modulatory effect of the DA agonist R-apomorphine on motor function, as previous studies have shown that following DA agonists significant alteration of spontaneous motor behavior occurs $[33,34]$. We preferred to use the open field test in this study to evaluate the animals in a drug-free state. Indeed, amphetamine induced rotation might influence the expression of genes, and our previous results already indicate that a subchronic R-apomorphine treatment of 6OHDA striatally lesioned rats reduced the amphetamine induced ipsilateral rotations [14]. 


\subsection{Sacrifice and Brain Prelevation}

Seventy-two hours (wash-out period) after the last injecttion of R-apomorphine (day 14), the rats were killed with an overdose of pentobarbital $\left(\right.$ Nembutal $^{\circledR}$, Ceva Sante Animale, Brussels, Belgium) and the brains were quickly removed without perfusion. From the rostral part $(10 \mathrm{~mm}$ from front) of the brain the left and right striatum were dissected out on an ice cold chilled petri-dish, immediately snap frozen in dry-ice cooled isopentane and stored separately at $-80^{\circ} \mathrm{C}$ until homogenisation and analysis of 1) striatal DA and DOPAC content, 2) striatal gene expression and 3) protein expression of CRHR1, CRHR2, and neuropeptide Y (NPY) receptors 1 and 2.

\subsection{Neurochemical Determination of the Striatal DA and DOPAC Content}

To establish the extent of DA and DOPAC depletion in the striatum after 6-OHDA lesioning, the liquid chromatography (LC) method previously described was used [14], with slight modifications.

The supernatant obtained during protein expression analysis (4.7) was diluted 5 times in antioxidant $(0.05 \mathrm{M}$ $\mathrm{HCl}, 0.5 \% \mathrm{Na}_{2} \mathrm{~S}_{2} \mathrm{O}_{5}$ and $0.05 \% \mathrm{Na}_{2}$ EDTA). $20 \mu \mathrm{l}$ of samples were injected and analysed directly for DA and DOPAC content on a narrowbore (C18 column: $15 \mathrm{~m}$, $150 \mathrm{~mm} \times 2.1 \mathrm{~mm}$; Altima; Grace; Lokeren; Belgium) LC system. The mobile phase consisted of $0.1 \mathrm{M}$ sodium acetate trihydrate, $20 \mathrm{mM}$ citric acid monohydrate, $1 \mathrm{mM}$ 1-octane sulfonic acid, $0.1 \mathrm{mM} \mathrm{Na} 2$ EDTA and $1 \mathrm{mM}$ dibutylamine, adjusted to $\mathrm{pH} 3.7$. Methanol $3 \%$ (v/v) was added as organic modifier. The flow rate was set at 0.2 $\mathrm{ml} / \mathrm{min}$. The electrochemical detection (Antec, The Netherlands) potential was $+700 \mathrm{mV}$ versus the reference electrode $(\mathrm{Ag} / \mathrm{AgCl})$. Sensitivity was set at $1 \mathrm{nA}$ full scale. All samples were injected via a high precision auto-injector equipped with a cooling system (Kontron, San Diego, CA, USA). The integration of the chromatograms was done with the Data Apex Clarity software program (Antec). The tissue DA and DOPAC content were calculated and expressed as $\mu \mathrm{g} / \mathrm{g}$ wet weight of tissue.

\subsection{Gene Expression Analysis}

\subsubsection{RNA Extraction}

Total RNA was extracted from the striatal tissue using the RNeasy ${ }^{\circledR}$ Lipid Tissue Mini Kit according to the manufacturer's protocol (Qiagen, Venlo, The Netherlands). The concentration and purity of RNA were determined by measuring the absorbance using the Nanodrop 1000 (Thermo Scientific). The quality of total RNA was assessed using the Agilent ${ }^{\circledR}$ Bioanalyzer RNA 6000 Nano Labchip ${ }^{\circledR}$ (Agilent Technologies, Palo Alto, CA).
For each RNA sample the presence of sharp bands/peaks present for both the $18 \mathrm{~S}$ and $28 \mathrm{~S}$ ribosomal RNAs were verified and only the samples with an RNA Integrity Number of 7 or higher were used.

One microgram of total RNA was subjected to first strand cDNA synthesis using the RT2 First Strand Kit (SA Biosciences, MD). For real-time PCR, a PCR components mix consisting of $2 \times$ RT2 SYBR Green Fluor qPCR Mastermix (1350 $\mu \mathrm{l})$ (SA Biosciences), cDNA synthesis reaction $(102 \mu \mathrm{l})$ and RNase-free water (1248 $\mu 1)$ was prepared. The final volume was $2700 \mu$ l, providing an excess volume to perform pipetting steps as precisely as possible to ensure that each well of the array receives the required volume. $25 \mu \mathrm{l}$ of the mixture was added into each of the wells of the RT ${ }^{2}$ Profiler PCR Arrays (PARN-031, SA Biosciences, MD)

\subsubsection{Quantitative Real-Time PCR}

Real-time quantifications were performed using the Bio$\operatorname{Rad}^{\circledR}$ iCycler $^{\circledR}$ Real-time PCR system (Bio-Rad) using the recommended cycling conditions for the $\mathrm{RT}^{2}$ Profiler PCR arrays (SA Biosciences, MD). Each PCR array contained 84 transcripts, a set of five housekeeping genes as internal controls and additional controls for efficiency of reverse transcription, PCR and the absence of contaminating genomic DNA.

Relative expression was determined with the $\Delta \Delta \mathrm{CT}$ method using the PCR Array Data Analysis Web Portal (www.SABiosciences.com/pcrarraydataanalysis.php) and the web based software automatically performed quantification, including the quality control for each PCR run/ array. For normalization of the expression levels of the genes of interest, the average $\mathrm{CT}$ value of the five housekeeping genes: Ribosomal protein, large, P1 (Rplp1); hypoxanthine phosphoribosyltransferase 1 (Hprt1); ribosomal protein L13A (Rpl13a); lactate dehydrogenase A (Ldha) and $\beta$-actin (Actb) was chosen. If the fold-change was greater than 1 , the result is reported as a fold upregulation. If the fold-change was less than 1 , the negative inverse of the results is reported as a fold downregulation.

\subsection{Protein Expression Analysis}

To measure CRHR1, CRHR2, NPY1R and NPY2R protein levels, the striatal tissue was homogenised in an icecold PBS-solution (0.02 M, pH 7.0 - 7.2) containing 2\% protease inhibitor cocktail (Sigma, St-Louis, MO, USA) (25 mg tissue/ml) and subsequently sonicated for $1 \mathrm{~min}$ (Branson Sonifier 250). After centrifugation at 10,000 g at $4^{\circ} \mathrm{C}$ during 10 minutes (Sorvall RC5B refrigated superspeed centrifuge, Dupont Instruments), the supernatants were collected and stored at $-20^{\circ} \mathrm{C}$ until use. After decantation, the protein content of the supernatant 
was determined by ELISA and the DA content by LC (4.5). Tissue levels of CRHR1, CRHR2, NPY1R and NPY2R were determined in $100 \mu \mathrm{l}$ aliquots by comercially available ELISA kits (USCN Life Science Inc., Wuhan, China) according to the manufacturer's instructions. Absorbances were measured using a Bio-Rad 680 microplate (Bio-Rad Laboratories, Belgium) reader set at $450 \mathrm{~nm}$. The protein content was determined using the Pierce $^{\circledR} 660 \mathrm{~nm}$ Protein Assay Kit (Thermo Scientific, USA).

\subsection{Data Analysis}

The web-based software of the company SA Biosciences has been used to analyse the gene expression data. All data are expressed as mean \pm S.E.M. Significant differences between all the experimental groups were determined using one-way analysis of variance (ANOVA) followed by the Bonferroni's post-hoc test. The significance of the change in gene expression between the groups was evaluated by unpaired Student t-test for each gene. All statistical analysis was performed with GraphPad Instat 3.0 (GraphPad Prism Software, Inc., San Diego, USA) at the $5 \%$ level of significance.

\section{Results}

\subsection{Neuroprotective Effect of R-Apomorphine in the Striatal 6-OHDA Rat Model (Figures 2 and 3)}

The neuroprotective effect of R-apomorphine was confirmed by determination of the striatal DA content and DA turnover (Figure 2) and in the open field test (Figure 3). Two weeks after injection of 6-OHDA, the DA content of the striata contralateral to the side of the lesion of rats receiving saline or R-apomorphine were not significantly different from those of the control animals (data not shown). However, the DA content of the le-

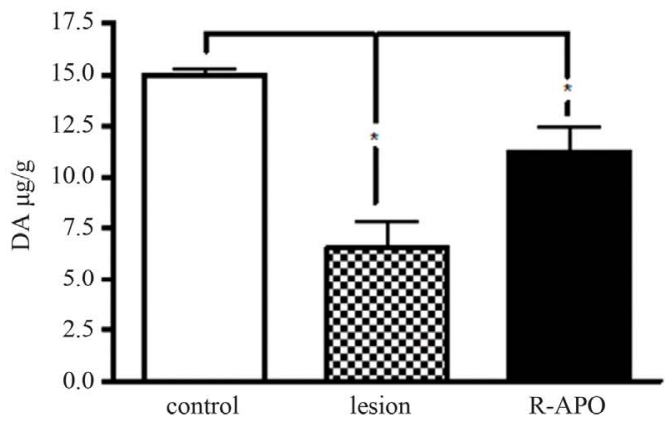

sioned striata of saline treated rats was significantly reduced after intrastriatal application of 6-OHDA by $60 \%$, similar to our previous findings [14]. The DOPAC:DA ratio in the denervated striatum of the striatally lesioned rats was significantly increased. Treatment with R-apomorphine started 15 min before the intrastriatal injection of 6-OHDA significantly attenuated the striatal DA depletion and restored the DOPAC:DA ratio. The beneficial neurochemical effects of the treatment with R-apomorphine were similar to our previous findings [14].

Recording of the open field activity (Figure 3) revealed that $\mathrm{R}$-apomorphine significantly attenuated the 6-OHDA induced reduction in total distance moved and increase in relative meander. There was a trend for Rapomorphine to improve the 6-OHDA lesion induced reduction in velocity $(\mathrm{p}=0.08)$. $\mathrm{R}$-apomorphine treatment had no effect on movement time, immobility time and rearing (data not shown).

\subsection{Gene Expression Analysis}

A list of the genes that have been screened with the corresponding fold changes is listed in Table $\mathbf{1}$.

\subsubsection{Gene Expression Profile of the Striatal 6-Hydroxydopamine Rat Model}

In the striatum, 20 genes out of the 84 genes on the array were changed in the striatally lesioned rats compared to non-lesioned rats. Significant differences were detected between the striatally lesioned rats and the non-lesioned rats for 14 out of the 20 genes $(p<0.05)$, with a further 6 genes nearing significance $(p<0.1)$. The majority of the genes (13) were upregulated in the striatal 6-OHDA rat model, whereas 7 were downregulated. Two weeks after the striatal administration of 6-OHDA, the expression of CRHR2, GFRA1, GFRA3, GMFG, CD40, CCKAR, TGFb1, CX3CR1, IL-10r $\alpha$, IL-6r $\alpha$, HSPB1, STAT1 and

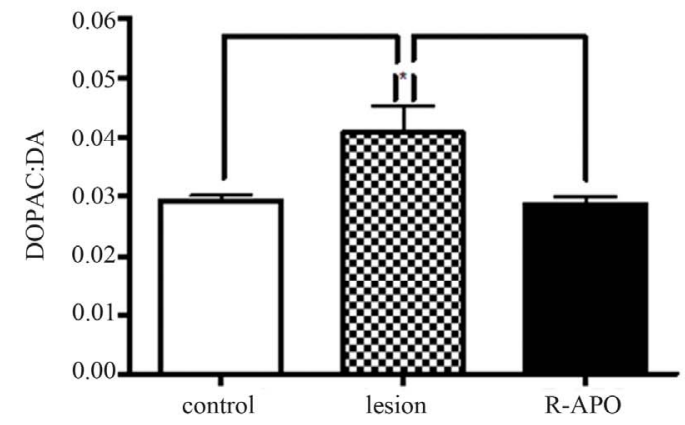

Figure 2. Dopamine levels and dopamine turnover. Dopamine (DA) content (left panel) and 3,4-dihydroxyphenylacetic acid (DOPAC) DOPAC:DA ratio (right panel) of the left striatum of control $(\mathrm{n}=6)$, saline treated 6-OHDA striatal lesioned $(\mathrm{n}=6$ ) and $R$-apomorphine treated 6-OHDA striatally lesioned rats $(n=6)$. DA content was determined two weeks after striatal micro-injection of 6-hydroxydopamine (6-OHDA) and is expressed as $\mu \mathrm{g} / \mathrm{g}$ wet tissue (mean \pm S.E.M). *Significantly different (one-way ANOVA followed by a Bonferroni's Multiple Comparison Test: $\mathbf{p}<0.05$ ). 

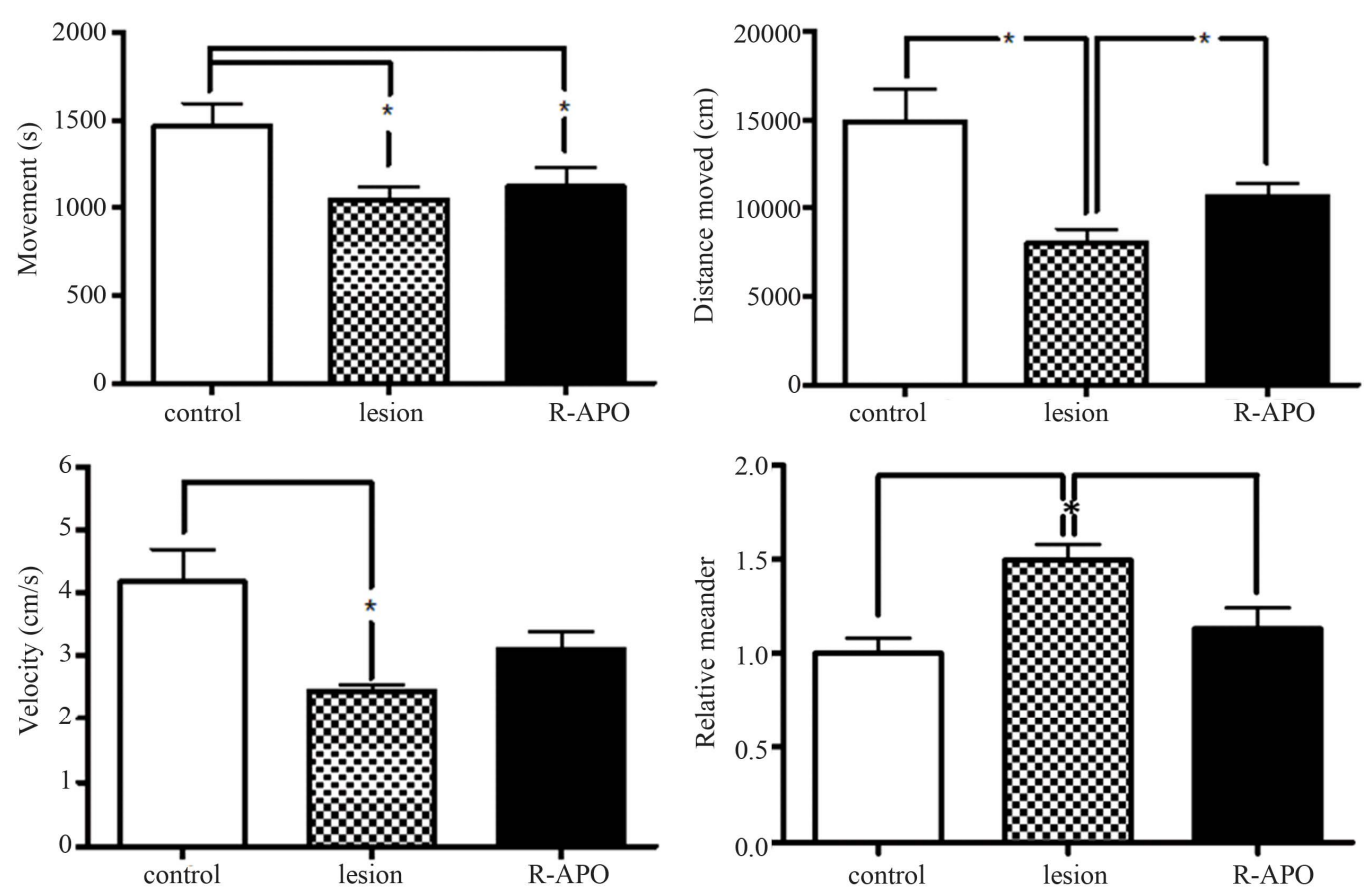

Figure 3. Open field activity. Locomotor activity of control $(n=5)$, saline treated 6-OHDA striatal lesioned $(n=5)$ and $R$ apomorphine treated 6-OHDA striatally lesioned rats $(n=6)$. The mean total distance moved (upper left panel), movement time (upper right panel), velocity (lower left panel) and relative meander (lower right panel) in the open field under unhabituated conditions are illustrated. The recording started immediately after placing animals in the open field and continued for $60 \mathrm{~min}$. Each performance was automatically analyzed using a video tracking system and Ethovision 3.0 tracking software (Noldus, the Netherlands). Data are expressed as mean \pm S.E.M. *Significantly different (one-way ANOVA followed by a Bonferroni's Multiple Comparison Test: $p<0.05)$.

Table 1. Striatal gene epression results obtained by quantitative real-time PCR. Gene expression in the control $(n=3)$, saline treated 6-OHDA striatal lesioned $(n=4)$ and R-apomorphine treated 6-OHDA striatal lesioned rats $(n=4)$ was analyzed using the Neurotrophins and Receptors RT $^{2}$ Profiler PCR Arrays (SA Biosciences) as described in Material and Methods. Relative expression is determined with the $\Delta \Delta \mathrm{CT}$ method. If the fold-change is greater than 1 , the result is reported as a fold upregulation. If the fold-change is less than 1 , the negative inverse of the results is reported as a fold downregulation. The p-values were calculated based on an unpaired Student's t-test for each gene. All the 84 genes and their functional classes are shown in the table.

\begin{tabular}{|c|c|c|c|c|c|c|}
\hline Description & Gene symbol & GenBank & $\begin{array}{c}\text { Fold } \\
\text { regulation } \\
\text { 6-OHDA } \\
\text { versus } \\
\text { control }\end{array}$ & p-value & $\begin{array}{c}\text { Fold } \\
\text { regulation } \\
\text { R-APO } \\
\text { versus } \\
\text { control }\end{array}$ & p-value \\
\hline \multicolumn{7}{|l|}{ Neurotrophins and Receptors } \\
\hline Adenylate cyclase activating polypeptide 1 receptor 1 & Adcyap1r1 & NM_133511 & -1.11 & 0.6471 & 1.07 & 0.9809 \\
\hline Artemin & Artn & NM_053397 & -1.11 & 0.6000 & -1.41 & 0.1508 \\
\hline Brain-derived neurotrophic factor & Bdnf & NM_012513 & 2.22 & 0.3474 & -1.08 & 0.8819 \\
\hline Ciliary neurotrophic factor & Cntf & NM_013166 & 1.10 & 0.5290 & 1.06 & 0.6760 \\
\hline Ciliary neurotrophic factor receptor & Cntfr & NM_001003929 & -1.15 & 0.5044 & -1.15 & 0.5441 \\
\hline Corticotropin releasing hormone & $\mathrm{Crh}$ & NM_031019 & -1.80 & 0.2127 & -2.15 & 0.1367 \\
\hline Corticotropin releasing hormone binding protein & Crhbp & NM_139183 & -1.15 & 0.5033 & -1.16 & 0.4726 \\
\hline Corticotropin releasing hormone receptor 1 & Crhr1 & NM_030999 & 1.04 & 0.7216 & 1.39 & 0.0632 \\
\hline
\end{tabular}




\begin{tabular}{|c|c|c|c|c|c|c|}
\hline Fibroblast growth factor receptor substrate 3 & Frs3 & NM_001017382 & 1.08 & 0.5453 & 1.22 & 0.1740 \\
\hline Glial cell derived neurotrophic factor & Gdnf & NM_019139 & -1.05 & 0.7042 & -1.17 & 0.4756 \\
\hline GDNF family receptor alpha 1 & Gfral & NM_012959 & 1.50 & 0.0999 & 1.40 & 0.1511 \\
\hline GDNF family receptor alpha 2 & Gfra2 & NM_012750 & -1.00 & 0.9577 & -1.14 & 0.6205 \\
\hline GDNF family receptor alpha 3 & Gfra3 & NM_053398 & 1.79 & 0.0435 & 1.26 & 0.0801 \\
\hline Glia maturation factor, beta & $\mathrm{Gmfb}$ & NM_031032 & 1.10 & 0.4245 & 1.26 & 0.0867 \\
\hline Glia maturation factor, gamma & Gmfg & NM_181091 & 1.70 & 0.0072 & 1.83 & 0.0032 \\
\hline Hypocretin (orexin) receptor 1 & Hcrtr1 & NM_013064 & 1.19 & 0.4072 & -1.08 & 0.9414 \\
\hline Hypocretin (orexin) receptor 2 & Hcrtr2 & NM_013074 & -1.05 & 0.8012 & -1.13 & 0.6321 \\
\hline Metallothionein 3 & Mt3 & NM_053968 & -1.11 & 0.4487 & -1.27 & 0.2408 \\
\hline Nerve growth factor (beta polypeptide) & $\mathrm{Ngfb}$ & XM_227525 & 1.20 & 0.2602 & 1.36 & 0.1124 \\
\hline $\begin{array}{l}\text { Nerve growth factor receptor (TNFR superfamily, } \\
\text { member 16) }\end{array}$ & Ngfr & NM_012610 & -1.06 & 0.8455 & 1.12 & 0.6659 \\
\hline $\begin{array}{l}\text { Nerve growth factor receptor (TNFRSF16) associated } \\
\text { protein } 1\end{array}$ & Ngfrap1 & NM_053401 & -1.48 & 0.0437 & -1.72 & 0.0339 \\
\hline Nuclear receptor subfamily 1 , group I, member 2 & Nr1i2 & NM_052980 & -1.23 & 0.3919 & -1.11 & 0.7157 \\
\hline Neuregulin 1 & $\operatorname{Nrg} 1$ & NM_031588 & -1.20 & 0.3026 & -1.26 & 0.2108 \\
\hline Neuregulin 2 & Nrg2 & XM_344662 & -1.01 & 0.9586 & 1.20 & 0.3032 \\
\hline Neurotrophin 3 & $\mathrm{Ntf3}$ & NM_031073 & 1.19 & 0.6292 & 1.78 & 0.1067 \\
\hline Neurotrophin 5 & Ntf5 & NM_013184 & -1.25 & 0.3904 & -1.96 & 0.4401 \\
\hline Neurotrophic tyrosine kinase, receptor, type 1 & Ntrk1 & NM_021589 & -1.82 & 0.0828 & -1.42 & 0.3921 \\
\hline Neurotrophic tyrosine kinase, receptor, type 2 & Ntrk2 & NM_012731 & -1.17 & 0.3840 & -1.44 & 0.1327 \\
\hline Persephin & Pspn & NM_013014 & -1.03 & 0.7075 & 1.04 & 0.7371 \\
\hline Prostaglandin E receptor 2 (subtype EP2) & Ptger2 & NM_031088 & -1.13 & 0.6021 & 1.08 & 0.9750 \\
\hline Trk-fused gene & Tfg & NM_001012144 & 1.01 & 0.9790 & 1.03 & 0.8562 \\
\hline CD40 molecule, TNF receptor superfamily member 5 & $\mathrm{Cd} 40$ & NM_134360 & 2.68 & 0.0003 & 3.27 & 0.0001 \\
\hline Fas (TNF receptor superfamily, member 6) & Fas & NM_139194 & 1.29 & 0.3149 & 1.64 & 0.1195 \\
\hline Urocortin & Ucn & NM_019150 & -1.17 & 0.5582 & -1.15 & 0.4268 \\
\hline VGF nerve growth factor inducible & Vgf & NM_030997 & -1.36 & 0.3562 & -1.42 & 0.1827 \\
\hline Zinc finger protein 110 & Zfp110 & NM_001024775 & -1.43 & 0.1192 & -1.68 & 0.0479 \\
\hline Zinc finger protein 91 & Zfp91 & NM_001169120 & -1.30 & 0.0316 & -1.53 & 0.0526 \\
\hline \multicolumn{7}{|l|}{ Neuropeptides and Receptors } \\
\hline \multicolumn{7}{|l|}{ Bombesin Receptors } \\
\hline Gastrin releasing peptide receptor & Grpr & NM_012706 & -1.79 & 0.0484 & -1.77 & 0.1867 \\
\hline \multicolumn{7}{|l|}{ Cholecystokinin Receptors } \\
\hline Cholecystokinin A receptor & Cckar & NM_012688 & 2.00 & 0.0897 & 2.15 & 0.1202 \\
\hline \multicolumn{7}{|l|}{ Galanin Receptors } \\
\hline Galanin receptor 1 & Galr1 & NM_012958 & -2.10 & 0.3045 & -1.83 & 0.1559 \\
\hline
\end{tabular}




\begin{tabular}{|c|c|c|c|c|c|c|}
\hline Galanin receptor 2 & Galr2 & NM_019172 & 1.03 & 0.7421 & 1.01 & 0.7771 \\
\hline \multicolumn{7}{|l|}{ Tachykinin Receptors } \\
\hline Tachykinin receptor 1 & Tacr1 & NM_012667 & -1.24 & 0.1941 & -1.06 & 0.8856 \\
\hline \multicolumn{7}{|l|}{ Other Neuropeptides and Receptors } \\
\hline Neuropeptide FF receptor 2 & Npffr2 & NM_023980 & -1.11 & 0.9903 & -1.32 & 0.8297 \\
\hline Hypocretin & HcRt & NM_013179 & -1.48 & 0.2752 & -1.23 & 0.3425 \\
\hline Melanocortin 2 receptor & $\mathrm{Mc} 2 \mathrm{r}$ & NM_001100491 & 1.65 & 0.3436 & 1.86 & 0.1214 \\
\hline Neuropeptide Y & Npy & NM_012614 & -1.10 & 0.4672 & -1.06 & 0.7078 \\
\hline Neuregulin 1 & $\operatorname{Nrg} 1$ & NM_031588 & -1.20 & 0.3026 & -1.26 & 0.2108 \\
\hline \multicolumn{7}{|l|}{$\underline{\text { Neurogenesis }}$} \\
\hline \multicolumn{7}{|l|}{ Central Nervous System Development } \\
\hline Chemokine $(\mathrm{C}-\mathrm{X}-\mathrm{C}$ motif) receptor 4 & Cxcr4 & NM_022205 & 1.19 & 0.4159 & -1.11 & 0.4334 \\
\hline Fibroblast growth factor receptor 1 & Fgfr1 & NM_024146 & 1.25 & 0.1320 & 1.26 & 0.1858 \\
\hline $\begin{array}{l}\text { Nerve growth factor receptor (TNFR superfamily, } \\
\text { member 16) }\end{array}$ & Ngfr & NM_012610 & -1.06 & 0.8455 & 1.12 & 0.6659 \\
\hline Neurotrophin 3 & $\mathrm{Ntf3}$ & NM_031073 & 1.19 & 0.6292 & 1.78 & 0.1067 \\
\hline \multicolumn{7}{|l|}{ Peripheral Nervous System Development } \\
\hline Artemin & Artn & NM_053397 & -1.11 & 0.6000 & -1.41 & 0.1508 \\
\hline Glial cell derived neurotrophic factor & Gdnf & NM_019139 & -1.05 & 0.7042 & -1.17 & 0.4756 \\
\hline GDNF family receptor alpha 3 & Gfra3 & NM_053398 & 1.79 & 0.0435 & 1.26 & 0.0801 \\
\hline Nerve growth factor (beta polypeptide) & $\mathrm{Ngfb}$ & XM_227525 & 1.20 & 0.2602 & 1.36 & 0.1124 \\
\hline Neuregulin 1 & $\operatorname{Nrg} 1$ & NM_031588 & -1.20 & 0.3026 & -1.26 & 0.2108 \\
\hline Neurotrophin 3 & $\mathrm{Ntf3}$ & NM_031073 & 1.19 & 0.6292 & 1.78 & 0.1067 \\
\hline \multicolumn{7}{|l|}{ Axon Guidance } \\
\hline Artemin & Artn & NM_053397 & -1.11 & 0.6000 & -1.41 & 0.1508 \\
\hline GDNF family receptor alpha 3 & Gfra3 & NM_053398 & 1.79 & 0.0435 & 1.26 & 0.0801 \\
\hline $\begin{array}{l}\text { Nerve growth factor receptor (TNFR superfamily, } \\
\text { member 16) }\end{array}$ & Ngfr & NM_012610 & -1.06 & 0.8455 & 1.12 & 0.6659 \\
\hline \multicolumn{7}{|l|}{ Gliogenesis } \\
\hline Fibroblast growth factor 2 & Fgf2 & NM_019305 & 1.24 & 0.3390 & 1.47 & 0.0259 \\
\hline Neuregulin 1 & $\operatorname{Nrg} 1$ & NM_031588 & -1.20 & 0.3026 & -1.26 & 0.2108 \\
\hline Neurotrophin 3 & $\mathrm{Ntf3}$ & NM_031073 & 1.19 & 0.6292 & 1.78 & 0.1067 \\
\hline \multicolumn{7}{|l|}{ Dendrite Morphogenesis } \\
\hline Brain-derived neurotrophic factor & Bdnf & NM_012513 & 2.22 & 0.3474 & -1.08 & 0.8819 \\
\hline Metallothionein 3 & Mt3 & NM_053968 & -1.11 & 0.4487 & -1.27 & 0.2408 \\
\hline \multicolumn{7}{|l|}{ Other Neurogenesis Genes } \\
\hline Bcl2-associated $\mathrm{X}$ protein & Bax & NM_017059 & -1.13 & 0.6256 & -1.09 & 0.5521 \\
\hline FBJ osteosarcoma oncogene & Fos & NM_022197 & 1.74 & 0.1261 & 3.29 & 0.0102 \\
\hline
\end{tabular}




\begin{tabular}{|c|c|c|c|c|c|c|}
\hline Galanin receptor 2 & Galr2 & NM_019172 & 1.03 & 0.7421 & 1.01 & 0.7771 \\
\hline GDNF family receptor alpha 1 & Gfra1 & NM_012959 & 1.50 & 0.0999 & 1.40 & 0.1511 \\
\hline GDNF family receptor alpha 2 & Gfra2 & NM_012750 & -1.00 & 0.9577 & -1.14 & 0.6205 \\
\hline NEL-like 1 (chicken) & Nell1 & NM_031069 & -1.08 & 0.5581 & 1.01 & 0.9296 \\
\hline Neurotrophin 5 & Ntf5 & NM_013184 & -1.25 & 0.3904 & -1.96 & 0.4401 \\
\hline Neurotrophic tyrosine kinase, receptor, type 1 & Ntrk1 & NM_021589 & -1.82 & 0.0828 & -1.42 & 0.3921 \\
\hline Neurotrophic tyrosine kinase, receptor, type 2 & Ntrk2 & NM_012731 & -1.17 & 0.3840 & -1.44 & 0.1327 \\
\hline \multicolumn{7}{|l|}{$\underline{\text { Synaptic Transmission }}$} \\
\hline Cerebellin 1 precursor & Cbln1 & NM_001109127 & -1.38 & 0.9382 & -1.64 & 0.6224 \\
\hline \multicolumn{7}{|l|}{ Growth and Differentiation } \\
\hline \multicolumn{7}{|l|}{ Growth Factors and Receptors } \\
\hline Artemin & Artn & NM_053397 & -1.11 & 0.6000 & -1.41 & 0.1508 \\
\hline Brain-derived neurotrophic factor & Bdnf & NM_012513 & 2.22 & 0.3474 & -1.08 & 0.8819 \\
\hline Fibroblast growth factor 2 & Fgf2 & NM_019305 & 1.24 & 0.3390 & 1.47 & 0.0259 \\
\hline Fibroblast growth factor 9 & Fgf9 & NM_012952 & 1.24 & 0.4508 & 1.17 & 0.5779 \\
\hline Fibroblast growth factor receptor 1 & Fgfr1 & NM_024146 & 1.25 & 0.1320 & 1.26 & 0.1858 \\
\hline Glial cell derived neurotrophic factor & Gdnf & NM_019139 & -1.05 & 0.7042 & -1.17 & 0.4756 \\
\hline Glia maturation factor, beta & $\mathrm{Gmfb}$ & NM_031032 & 1.10 & 0.4245 & 1.26 & 0.0867 \\
\hline Glia maturation factor, gamma & Gmfg & NM_181091 & 1.70 & 0.0072 & 1.83 & 0.0032 \\
\hline Interleukin 10 & Il10 & NM_012854 & 1.35 & 0.4768 & -1.02 & 0.7271 \\
\hline Interleukin 1 beta & Illb & NM_031512 & 2.50 & 0.1685 & 3.16 & 0.0035 \\
\hline Interleukin 6 & Il6 & NM_012589 & -1.21 & 0.3849 & 1.46 & 0.6407 \\
\hline Leukemia inhibitory factor & Lif & NM_022196 & 1.57 & 0.3027 & 2.17 & 0.0687 \\
\hline Metallothionein 3 & Mt3 & NM_053968 & -1.11 & 0.4487 & -1.27 & 0.2408 \\
\hline Nerve growth factor (beta polypeptide) & $\mathrm{Ngfb}$ & XM_227525 & 1.20 & 0.2602 & 1.36 & 0.1124 \\
\hline Neuregulin 2 & $\mathrm{Nrg} 2$ & XM_344662 & -1.01 & 0.9586 & 1.20 & 0.3032 \\
\hline Neurotrophin 3 & Ntf3 & NM_031073 & 1.19 & 0.6292 & 1.78 & 0.1067 \\
\hline Neurotrophin 5 & Ntf5 & NM_013184 & -1.25 & 0.3904 & -1.96 & 0.4401 \\
\hline Persephin & Pspn & NM_013014 & -1.03 & 0.7075 & 1.04 & 0.7371 \\
\hline Transforming growth factor alpha & Tgfa & NM_012671 & 1.23 & 0.1619 & 1.22 & 0.1567 \\
\hline Transforming growth factor, beta 1 & Tgfb1 & NM_021578 & 2.90 & 0.0029 & 3.36 & 0.0001 \\
\hline Transforming growth factor beta 1 induced transcript 1 & Tgfb1i1 & XM_341934 & 1.21 & 0.2067 & 1.20 & 0.3595 \\
\hline Tumor protein p53 & Tp53 & NM_030989 & -1.10 & 0.5051 & 1.10 & 0.6728 \\
\hline VGF nerve growth factor inducible & Vgf & NM_030997 & -1.36 & 0.3562 & -1.42 & 0.1827 \\
\hline \multicolumn{7}{|l|}{ Cell cycle } \\
\hline Fibroblast growth factor 2 & Fgf2 & NM_019305 & 1.24 & 0.3390 & 1.47 & 0.0259 \\
\hline Fibroblast growth factor 9 & Fgf9 & NM_012952 & 1.24 & 0.4508 & 1.17 & 0.5779 \\
\hline
\end{tabular}




\begin{tabular}{|c|c|c|c|c|c|c|}
\hline Interleukin 1 beta & $\mathrm{Il1b}$ & NM_031512 & 2.50 & 0.1685 & 3.16 & 0.0035 \\
\hline Neurotrophic tyrosine kinase, receptor, type 1 & Ntrk1 & NM_021589 & -1.82 & 0.0828 & -1.42 & 0.3921 \\
\hline Transforming growth factor alpha & Tgfa & NM_012671 & 1.23 & 0.1619 & 1.22 & 0.1567 \\
\hline Transforming growth factor, beta 1 & Tgfb1 & NM_021578 & 2.90 & 0.0029 & 3.36 & 0.0001 \\
\hline Tumor protein $\mathrm{p} 53$ & $\operatorname{Tp} 53$ & NM_030989 & -1.10 & 0.5051 & 1.10 & 0.6728 \\
\hline \multicolumn{7}{|l|}{ Cell Proliferation } \\
\hline Bcl2-associated $\mathrm{X}$ protein & Bax & NM_017059 & -1.13 & 0.6256 & -1.09 & 0.5521 \\
\hline Chemokine ( $\mathrm{C}-\mathrm{X}-\mathrm{C}$ motif) receptor 4 & Cxcr4 & NM_022205 & 1.19 & 0.4159 & -1.11 & 0.4334 \\
\hline Fibroblast growth factor 2 & Fgf2 & NM_019305 & 1.24 & 0.3390 & 1.47 & 0.0259 \\
\hline Fibroblast growth factor 9 & Fgf9 & NM_012952 & 1.24 & 0.4508 & 1.17 & 0.5779 \\
\hline Gastrin releasing peptide receptor & Grpr & NM_012706 & -1.79 & 0.0484 & -1.77 & 0.1867 \\
\hline Interleukin 10 & $\mathrm{Il10}$ & NM_012854 & 1.35 & 0.4768 & -1.02 & 0.7271 \\
\hline Interleukin 1 beta & $\mathrm{Il} 1 \mathrm{~b}$ & NM_031512 & 2.50 & 0.1685 & 3.16 & 0.0035 \\
\hline Myelocytomatosis oncogene & Myc & NM_012603 & 1.26 & 0.2614 & 1.67 & 0.0109 \\
\hline Signal transducer and activator of transcription 4 & Stat4 & NM_001012226 & 1.64 & 0.2469 & 1.38 & 0.4436 \\
\hline Transforming growth factor alpha & Tgfa & NM_012671 & 1.23 & 0.1619 & 1.22 & 0.1567 \\
\hline Transforming growth factor, beta 1 & Tgfb1 & NM_021578 & 2.90 & 0.0029 & 3.36 & 0.0001 \\
\hline Tumor protein p53 & $\mathrm{Tp} 53$ & NM_030989 & -1.10 & 0.5051 & 1.10 & 0.6728 \\
\hline \multicolumn{7}{|l|}{ Cell Differentiation } \\
\hline Ciliary neurotrophic factor & Cntf & NM_013166 & 1.10 & 0.5290 & 1.06 & 0.6760 \\
\hline Fibroblast growth factor 2 & Fgf2 & NM_019305 & 1.24 & 0.3390 & 1.47 & 0.0259 \\
\hline Fibroblast growth factor 9 & Fgf9 & NM_012952 & 1.24 & 0.4508 & 1.17 & 0.5779 \\
\hline Neurofibromin 1 & Nf1 & NM_012609 & -1.36 & 0.0706 & -1.34 & 0.0954 \\
\hline Neuregulin 1 & $\operatorname{Nrg} 1$ & NM_031588 & -1.20 & 0.3026 & -1.26 & 0.2108 \\
\hline Signal transducer and activator of transcription 3 & Stat3 & NM_012747 & 1.27 & 0.3093 & 1.33 & 0.2001 \\
\hline Tumor protein $\mathrm{p} 53$ & Tp53 & NM_030989 & -1.10 & 0.5051 & 1.10 & 0.6728 \\
\hline Zinc finger protein 91 & Zfp91 & NM_001169120 & -1.30 & 0.0316 & -1.53 & 0.0526 \\
\hline \multicolumn{7}{|l|}{ Cytokines and Receptors } \\
\hline Chemokine $(\mathrm{C}-\mathrm{X} 3-\mathrm{C}$ motif) receptor 1 & $\mathrm{Cx} 3 \mathrm{cr} 1$ & NM_133534 & 1.67 & 0.0315 & 1.70 & 0.0635 \\
\hline Chemokine $(\mathrm{C}-\mathrm{X}-\mathrm{C}$ motif) receptor 4 & Cxcr4 & NM_022205 & 1.19 & 0.4159 & -1.11 & 0.4334 \\
\hline Interleukin 10 & $\mathrm{Il10}$ & NM_012854 & 1.35 & 0.4768 & -1.02 & 0.7271 \\
\hline Interleukin 10 receptor, alpha & Il10ra & NM_057193 & 1.73 & 0.0500 & 1.71 & 0.0292 \\
\hline Interleukin 1 beta & Illb & NM_031512 & 2.50 & 0.1685 & 3.16 & 0.0035 \\
\hline Interleukin 1 receptor, type I & Il1r1 & NM_013123 & 1.22 & 0.2624 & 1.20 & 0.4294 \\
\hline Interleukin 6 & Il6 & NM_012589 & -1.21 & 0.3849 & 1.46 & 0.6407 \\
\hline Interleukin 6 receptor & I16r & NM_017020 & 1.60 & 0.0157 & 1.40 & 0.1988 \\
\hline Interleukin 6 signal transducer & Il6st & NM_001008725 & 1.08 & 0.3498 & 1.10 & 0.3305 \\
\hline
\end{tabular}




\begin{tabular}{|c|c|c|c|c|c|c|}
\hline Leukemia inhibitory factor & Lif & NM_022196 & 1.57 & 0.3027 & 2.17 & 0.0687 \\
\hline Leukemia inhibitory factor receptor alpha & Lifr & NM_031048 & -1.43 & 0.1643 & -1.47 & 0.1204 \\
\hline Neuregulin 1 & $\operatorname{Nrg} 1$ & NM_031588 & -1.20 & 0.3026 & -1.26 & 0.2108 \\
\hline Signal transducer and activator of transcription 4 & Stat4 & NM_001012226 & 1.64 & 0.2469 & 1.38 & 0.4436 \\
\hline \multicolumn{7}{|l|}{ Apoptosis } \\
\hline \multicolumn{7}{|l|}{ Anti-apoptosis } \\
\hline B-cell CLL/lymphoma 2 & $\mathrm{Bcl} 2$ & NM_016993 & -1.16 & 0.4948 & -1.34 & 0.2575 \\
\hline Brain-derived neurotrophic factor & Bdnf & NM_012513 & 2.22 & 0.3474 & -1.08 & 0.8819 \\
\hline Interleukin 10 & Il10 & NM_012854 & 1.35 & 0.4768 & -1.02 & 0.7271 \\
\hline \multicolumn{7}{|l|}{ Caspase Activation } \\
\hline Bcl2-associated $\mathrm{X}$ protein & Bax & NM_017059 & -1.13 & 0.6256 & -1.09 & 0.5521 \\
\hline Myelocytomatosis oncogene & Myc & NM_012603 & 1.26 & 0.2614 & 1.67 & 0.0109 \\
\hline Tumor protein $\mathrm{p} 53$ & Tp53 & NM_030989 & -1.10 & 0.5051 & 1.10 & 0.6728 \\
\hline \multicolumn{7}{|l|}{ Induction of Apoptosis } \\
\hline Bcl2-associated X protein & Bax & NM_017059 & -1.13 & 0.6256 & -1.09 & 0.5521 \\
\hline Myelocytomatosis oncogene & Myc & NM_012603 & 1.26 & 0.2614 & 1.67 & 0.0109 \\
\hline $\begin{array}{l}\text { Nerve growth factor receptor (TNFR superfamily, } \\
\text { member } 16 \text { ) }\end{array}$ & Ngfr & NM_012610 & -1.06 & 0.8455 & 1.12 & 0.6659 \\
\hline $\begin{array}{l}\text { Nerve growth factor receptor (TNFRSF16) associated } \\
\text { protein } 1\end{array}$ & Ngfrap1 & NM_053401 & -1.48 & 0.0437 & -1.72 & 0.0339 \\
\hline Fas (TNF receptor superfamily, member 6) & Fas & NM_139194 & 1.29 & 0.3149 & 1.64 & 0.1195 \\
\hline Tumor protein $\mathrm{p} 53$ & Tp53 & NM_030989 & -1.10 & 0.5051 & 1.10 & 0.6728 \\
\hline \multicolumn{7}{|l|}{ Other Apoptosis Genes } \\
\hline Heat shock protein 1 & Hspb1 & NM_031970 & 3.86 & 0.0231 & 4.21 & 0.0075 \\
\hline Interleukin 6 & Il6 & NM_012589 & -1.21 & 0.3849 & 1.46 & 0.6407 \\
\hline CD40 molecule, TNF receptor superfamily member 5 & $\mathrm{Cd} 40$ & NM_134360 & 2.68 & 0.0003 & 3.27 & 0.0001 \\
\hline \multicolumn{7}{|l|}{$\underline{\text { Immune response }}$} \\
\hline \multicolumn{7}{|l|}{ Acute-phase response } \\
\hline Interleukin 6 & Il6 & NM_012589 & -1.21 & 0.3849 & 1.46 & 0.6407 \\
\hline Signal transducer and activator of transcription 3 & Stat3 & NM_012747 & 1.27 & 0.3093 & 1.33 & 0.2001 \\
\hline \multicolumn{7}{|l|}{ Inflammatory response } \\
\hline Interleukin 10 & Il10 & NM_012854 & 1.35 & 0.4768 & -1.02 & 0.7271 \\
\hline Interleukin 1 beta & Illb & NM_031512 & 2.50 & 0.1685 & 3.16 & 0.0035 \\
\hline Transforming growth factor, beta 1 & Tgfb1 & NM_021578 & 2.90 & 0.0029 & 3.36 & 0.0001 \\
\hline \multicolumn{7}{|l|}{ Lymphocyte activation } \\
\hline Interleukin 10 & Il10 & NM_012854 & 1.35 & 0.4768 & -1.02 & 0.7271 \\
\hline CD40 molecule, TNF receptor superfamily member 5 & $\mathrm{Cd} 40$ & NM_134360 & 2.68 & 0.0003 & 3.27 & 0.0001 \\
\hline Other immune response genes & & & & & & \\
\hline
\end{tabular}




\begin{tabular}{|c|c|c|c|c|c|c|}
\hline Leukemia inhibitory factor & Lif & NM_022196 & 1.57 & 0.3027 & 2.17 & 0.0687 \\
\hline Fas (TNF receptor superfamily, member 6) & Fas & NM_139194 & 1.29 & 0.3149 & 1.64 & 0.1195 \\
\hline \multicolumn{7}{|l|}{ Transcription factors and regulators } \\
\hline \multicolumn{7}{|l|}{ Positive regulation of transcription } \\
\hline $\begin{array}{c}\text { Fusion (involved in } \mathrm{t}(12 ; 16) \text { in malignant liposarcoma) } \\
\text { (human) }\end{array}$ & Fus & NM_001012137 & -1.18 & 0.2780 & -1.14 & 0.3574 \\
\hline Neurotrophin 3 & $\mathrm{Ntf3}$ & NM_031073 & 1.19 & 0.6292 & 1.78 & 0.1067 \\
\hline Transforming growth factor beta 1 induced transcript 1 & Tgfbli1 & XM_341934 & 1.21 & 0.2067 & 1.20 & 0.3595 \\
\hline \multicolumn{7}{|l|}{ Transcription coactivator activity } \\
\hline Melanoma antigen, family D, 1 & Maged1 & NM_053409 & -1.34 & 0.0279 & -1.36 & 0.0508 \\
\hline Transforming growth factor beta 1 induced transcript 1 & Tgfbli1 & XM_341934 & 1.21 & 0.2067 & 1.20 & 0.3595 \\
\hline \multicolumn{7}{|l|}{ Other transcription factors and regulators } \\
\hline FBJ osteosarcoma oncogene & Fos & NM_022197 & 1.74 & 0.1261 & 3.29 & 0.0102 \\
\hline Myelocytomatosis oncogene & Myc & NM_012603 & 1.26 & 0.2614 & 1.67 & 0.0109 \\
\hline Nuclear receptor subfamily 1 , group I, member 2 & $\mathrm{Nr} 1 \mathrm{i} 2$ & NM_052980 & -1.23 & 0.3919 & -1.11 & 0.7157 \\
\hline Similar to myocyte enhancer factor $2 \mathrm{C}$ & LOC685671 & XR_006259 & 1.08 & 0.5206 & 1.20 & 0.4123 \\
\hline Signal transducer and activator of transcription 1 & Stat1 & NM_032612 & 1.82 & 0.0014 & 1.61 & 0.0042 \\
\hline Signal transducer and activator of transcription 2 & Stat2 & NM_001011905 & 1.23 & 0.0877 & 1.22 & 0.2499 \\
\hline Signal transducer and activator of transcription 3 & Stat3 & NM_012747 & 1.27 & 0.3093 & 1.33 & 0.2001 \\
\hline Signal transducer and activator of transcription 4 & Stat4 & NM_001012226 & 1.64 & 0.2469 & 1.38 & 0.4436 \\
\hline Tumor protein $\mathrm{p} 53$ & $\operatorname{Tp} 53$ & NM_030989 & -1.10 & 0.5051 & 1.10 & 0.6728 \\
\hline Zinc finger protein 110 & Zfp110 & NM_001024775 & -1.43 & 0.1192 & -1.68 & 0.0479 \\
\hline
\end{tabular}

STAT2 was upregulated, whereas the expression of NGFRAP1, NTRK1，ZFP91，GRPR，NPY2R，NF1, MAGED1 was downregulated.

\subsubsection{Gene Expression Profile in the R-Apomorphine Treated Striatally 6-Hydroxydopamine Lesioned Rats}

R-apomorphine treatment of the striatally lesioned 6OHDA rats changed the striatal expression of 20 genes out of the 84 genes on the array compared to the nonlesioned rats. Significant differences were detected between the R-apomorphine treated striatally lesioned rats and the non-lesioned rats for 13 genes out of 20 genes ( $p$ $<0.05$ ), with a further 7 genes nearing significance ( $\mathrm{p}<$ $0.1)$. The majority of the genes (15) were upregulated in the R-apomorphine treated striatally lesioned rats, whereas 5 were downregulated. An upregulation was found for the genes CRHR1, GFRA3, GMFB, GMFG, CD40, FGF2, FOS, IL-1b, LIF, TGFb1, MYC, CX3CR1, IL10r $\alpha$, HSPB1 and STAT1, whereas the expression of NGFRAP1, ZFP110, ZFP91, NF1 and MAGED1 was downregulated.

The changes in expression level of some genes were similar in both the striatally lesioned and the R-apomorphine treated 6-OHDA striatally lesioned rats versus the non-lesioned rats, such as the upregulation of GFRA3, CD40, TFGb1, CX3CR1, IL-10r $\alpha$, HSPB1 and STAT1, and the downregulation of NGFRAP1, ZFP91, NF1 and MAGED1.

The upregulation of GFRA1, CCKAR, IL-6r $\alpha$ and STAT2 in the striatum of striatally lesioned rats was either prevented or not different in the R-apomorphine treated striatally lesioned rats versus the non-lesioned rats.

Furthermore, a downregulation was observed for NTRK1, GRPR and NPY2R in the striatally lesioned rats, while the expression levels of these genes in the R-apomorphine treated striatally lesioned rats were not different from the non-lesioned rats. ZFP110 was significantly downregulated in the treated striatally lesioned rats versus the controls, whereas its expression in the striatally lesioned rats was not different from the non-lesioned rats. 
Based on the global overview of the gene expression alterations, we chose to focus on the neuropeptide recaptors CRHR1, CRHR2, NPY1R and NPY2R. These 4 receptors are all $\mathrm{G}$ protein coupled receptors (GPCRs) and have been implicated as potential drug targets in the treatment of Parkinson's disease, and are more extensively described in the discussion section. Regarding these neuropeptide receptors the following findings were observed. The expression level of CRHR1 was not significantly different between non-lesioned and striatally lesioned rats. However, in the R-apomorphine treated striatally lesioned rats an upregulation of the expression of CRHR1 ( $p=0.06)$ was observed when compared to non-lesioned rats. Although this upregulation was nearing significance, there was no difference when compared to striatally lesioned rats (Figure 4).

In the same way, a significant upregulation was found for CRHR2 in the striatally lesioned rats versus the nonlesioned and the treated striatally lesioned rats, whereas no significant difference was found between the R-apomorphine treated striatally lesioned rats and the nonlesioned rats, suggesting that the treatment normalized or prevented the upregulation of CRHR2 (Figure 4).
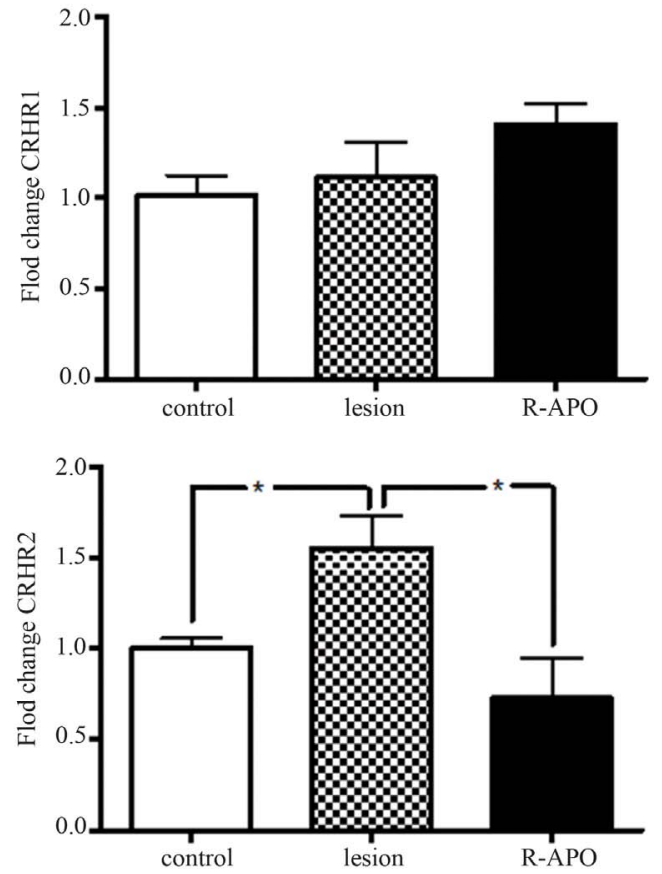

Regarding the NPY1R, there was a downregulation in the striatally lesioned rats versus the non-lesioned rats, but this was not statistically significant. However, a significant downregulation was observed in the striatally lesioned rats compared to the $\mathrm{R}$-apomorphine treated striatally lesioned rats. There was no significant difference between non-lesioned and R-apomorphine treated striatally lesioned rats, suggesting that R-apomorphine normalized or prevented changes in the expression level of NPY1R (Figure 5).

NPY2R was significantly downregulated in the striatally lesioned rats when compared to the non-lesioned rats. This downregulation was either prevented or normalized by R-apomorphine, as no significant differences were observed between the R-apomorphine treated striatally lesioned and non-lesioned rats (Figure 5).

\subsection{Protein Expression of CRHR1, CRHR2, NPY1R and NPY2R}

CRHR1 and CRHR2 protein levels, quantified with ELISA, confirmed the results of the gene expression analysis. The CRHR1 protein content in the denervated
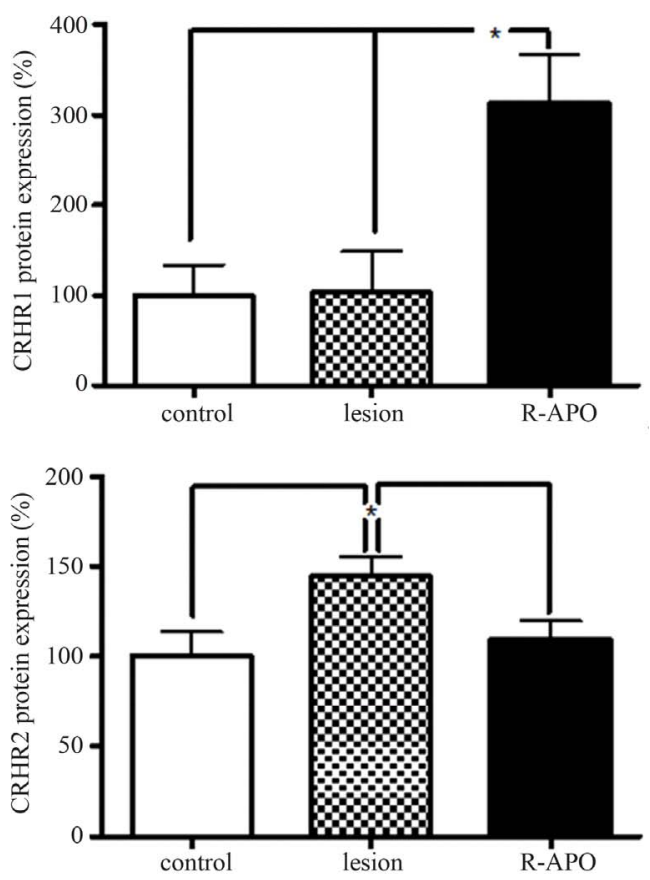

Figure 4. CRHR1 and CRHR2 mRNA and protein expression. CRHR1 (upper left panel) and CRHR2 (lower left panel) mRNA expression in the left striatum of control $(n=3)$, saline treated 6-OHDA striatal lesioned $(n=4)$ and R-apomorphine treated 6-OHDA striatally lesioned rats $(n=4)$ was determined using quantitative real-time PCR as described in the Methods. A fold-change greater than 1 is reported as up regulation, while lower than 1 is reported as down regulation. The protein expression of CRHR1 (upper right panel) and CRHR2 (lower right panel) in the left striatum in all the groups [(control $(\mathrm{n}=$ 6), saline treated 6-OHDA striatal lesioned $(n=6)$ and R-apomorphine treated 6-OHDA striatally lesioned rats $(n=6)]$ was determined using ELISA as described in the Methods. For each protein, the average control was set to $100 \%$. Data are expressed as mean \pm S.E.M. *Significantly different (one-way ANOVA followed by a Bonferroni's Multiple Comparison Test: $p$ $<0.05)$. 

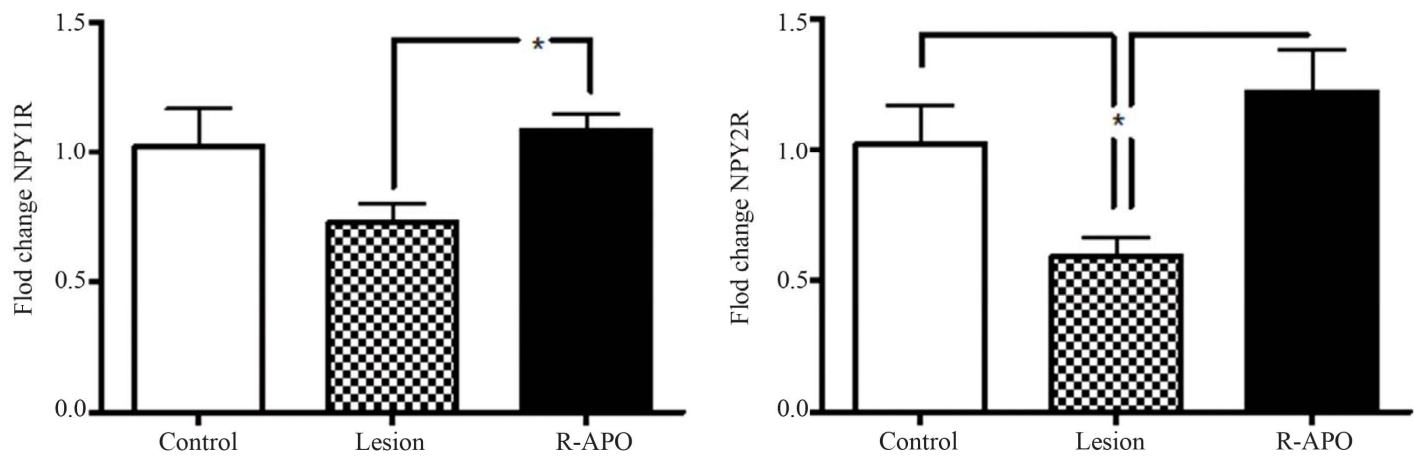

Figure 5. NPY1R and NPY2R mRNA expression. NPYR1 (left panel) and NPYR2 (right panel) mRNA expression in the left striatum of control $(n=3)$, saline treated 6-OHDA striatal lesioned $(n=4)$ and R-apomorphine treated 6-OHDA striatally lesioned rats $(n=4)$ was determined using quantitative real-time PCR as described in the Methods. A fold-change greater than 1 is reported as up regulation, while lower than 1 is reported as down regulation. Data are expressed as mean \pm S.E.M. *Significantly different (one-way ANOVA followed by a Bonferroni's Multiple Comparison Test: $\mathbf{p}<0.05$ ).

striata of the R-apomorphine treated striatally lesioned rats was significantly higher when compared to the left striata of the non-lesioned and the denervated striata of the striatally lesioned rats, while the CRHR1 protein content in the striata of non-lesioned rats and the denervated striata of striatally lesioned rats was not significantly different (Figure 4). CRHR2 protein levels of the denervated striata of the striatally lesioned rats were significantly higher when compared to the left striata of non-lesioned rats and the denervated striata of the Rapomorphine treated striatally lesioned rats, with no statistical difference between the R-apomorphine group and the control group (Figure 4).

No significant changes in NPY1R and NPY2R protein levels were detected in the left striata between the three groups (data not shown), suggesting that these receptors might not be involved in the biological action of Rapomorphine. However, this method does not monitor post-transcriptional and post-translational modifications, and it provides only a partial picture of the biological events [35].

\section{Discussion}

Our data show that R-apomorphine treatment $(10 \mathrm{mg} / \mathrm{kg}$ / day, s.c., during 11 days) of rats striatally lesioned with 6-OHDA is associated with a partial restoration of the DA levels and the DOPAC:DA ratios in the ipsilateral striatum. Furthermore, in the open field test an improvement in distance moved and attenuation of the relative meander was observed. The decreased locomotor activity, such as in the lesioned rats, has been attributed to the loss of DA neurotransmission [36]. The reason that not all the investigated behavioural parameters assessed during the open field test normalised or improved, might be due to the fact that R-apomorphine does not fully restore the neuronal degeneration caused by 6-OHDA, which is in line with the observed partial neuroprotection. These data confirm our previous findings where the same treatment with $\mathrm{R}$-apomorphine significantly reduced the amphetamine-induced rotations, attenuated the DA levels and the DOPAC:DA ratios, and subsequently suggest that the functionality and the integrity of the nigrostriatal dopaminergic system have at least partially been preserved by a treatment with R-apomorphine [14].

The gene expression analysis demonstrated that different genes are altered in the lesioned striatum of the saline treated striatally lesioned rats and the R-apomorphine treated striatally lesioned rats. Genes that were altered in the saline treated striatally lesioned rats, are related to the regulation of neurotrophins, neuropeptides, immune response, neurogenesis, growth and differentiation, cell cycle, cell proliferation, apoptosis and transcription factors and regulators, suggesting that different major events occur which might be involved in the molecular pathways of the pathogenesis of Parkinson's disease and confirming the complexity of the disorder. Treatment with R-apomorphine of the striatally lesioned rats did not reverse all the gene alterations that were observed in the saline treated striatally lesioned rats.

A role for inflammation in the striatal 6-OHDA rat model can be suggested from our data as several inflammatory-related genes were upregulated, such as CX3CR1, IL6R, IL10RA, TGFB1, and CD40. The concept of neuroinflammation as a primary response to 6-OHDA in both the striatum and the substantia nigra has been confirmed by $\mathrm{Na}$ et al., 2010 [37]. Furthermore, the DAergic neuronal loss within the striatal 6-OHDA rat model is preceded by microglial activation [38,39], suggesting a temporal relationship between neurodegeneration and neuroinflammation [39]. Similarly, in vivo and postmortem observations from Parkinson's disease patients show that indeed activated microglia are present and that the 
levels of pro-inflammatory mediators, such as TNF- $\alpha$, IL-6, IL-1 $\beta$, are increased [40]. All these findings substantiate the hypothesis of a fundamental role of inflammation in neurodegeneration.

Similarly, the brain alteration in the MPTP mouse model of Parkinson's disease has been investigated by others using a cDNA expression array including 1200 genes fragments and identified 51 genes in the MPTP mouse model related to similar major events and alterations in genes, such as a general increase in IL-1 $\beta$, IL-6 and IL-7, as well as in IL-1R, IL-2R, IL-3R and IL-4R, which confirms the concept of inflammation in neurodegeneration [9]. Pretreatment with R-apomorphine (10 $\mathrm{mg} / \mathrm{kg} /$ day, s.c.) for 5 days before MPTP $(24 \mathrm{mg} / \mathrm{kg} /$ day $)$ injections, reversed most of the gene alterations, suggesting a possible anti-inflammatory action. Furthermore, an increase in anti-inflammatory cytokine IL-10 mRNA might reflect an attempt to protect the neurons from further degeneration [9]. Although, the pharmacogenetic profile of the drug R-apomorphine was already investigated in the above mentioned study, major differences with our experimental set-up are the rodent model, the administration mode of R-apomorphine and some of the selected genes for the screening. For instance, R-apomorphine was administrated before the MPTP injections for 5 consecutive days by Grunblatt et al. (2001), while in our study the treatment started 15 min before the lesion induction and continued for 10 days [9].

Based on the global overview of the gene expression alterations (Table 1), we chose to focus on the GPCR neuropeptide receptors CRHR1, CRHR2, NPY1R and NPY2R. GPCRs represent a class of proteins with significant clinical importance, as approximately $30 \%$ of all modern therapeutic treatments target these receptors [41]. Furthermore, literature reports, as discussed below, suggest that these four receptors might have relevance as potential drug targets in the treatment of Parkinson's disease.

It has been demonstrated that activation of CRHR1 is anti-inflammatory [42] and that urocortin, a CRH-like peptide, restores key deficits, such as motor behavior, striatal DA levels and dopaminergic cell death in a LPS rat model of Parkinson's disease via CRHR1 [43-45] and protects against excitotoxic cell death via the same receptor [46]. Furthermore, the neuroprotective and neurorestorative effects of urocortin in the 6-OHDA rat model are mediated via CRHR1 [43-45]. The anti-inflammatory properties of urocortin in the periphery were previously reported by Gonzalez-Rey [47]. Huang et al. have also shown that urocortin modulates dopaminergic neuronal survival via inhibition of glycogen synthase kinase- $3 \beta$ and histone deacetylase [48]. In addition, Kim et al. confirmed the downstream properties of urocortin on $\mathrm{MPP}^{+}$treated neuroblastoma cells and its mediation via the activation of CRHR1 [49]. Further findings demonstrate that the activation of CRHR2 is pro-inflammatory in the periphery as it mediates the inflammatory responses via release of pro-inflammatory mediators at the colonocyte level [50,51]. Our data show that R-apomorphine treatment is associated with a downregulation of the pro-inflammatory CRHR2, and an upregulation of the anti-inflammatory CRHR1, both at mRNA and at protein levels.

Regarding the NPY receptors, Decressac et al. demonstrated that neuroproliferation in vivo is mediated by NPY1R [52]. Furthermore, NPY has an anti-inflammatory effect that is mediated by NPY1R in vivo [53]. More recently, Decressac et al. have shown that NPY is neuroprotective in in vivo models of Parkinson's disease via the NPY2 receptor via activation of both MAPK and Akt pathways [54]. Similarly, Thiriet et al. have shown that the intracerebral administration of NPY in mice blocked methamphetamine induced apoptosis and that this effect was mainly mediated by the stimulation of the NPY2 receptor and to a lesser extent by NPY1 receptors [55]. Moreover, it has been shown that the NPY receptors are involved in the attenuation of DA release in vitro $[36,56]$ and in vivo $[36,57,58]$ and that the NPY2 receptor is involved in DA synthesis in the rat striatum [36] and the inhibition of glutamate release [59]. Regarding these NPY receptors, our data demonstrates that R-apomorphine treatment is associated with an upregulation of the NPY1R and NPY2R at mRNA level, but not at the protein level. However, it is important to note that changes in mRNA levels are not always reflected by changes in protein expression since proteins can be synthesized in one brain area and afterwards transported to another [60]. Furthermore, post-transcriptional and post-translational modifications may occur [61].

$\mathrm{R}$-apomorphine has been already tested in vitro and various different observations have been registered [21, $26,27,62]$. It has been shown previously that R-apomorphine stimulates the synthesis and release of multiple trophic factors, such as brain-derived neurotrophic factor (BDNF) and glial cell line-derived neurotrophic factor (GDNF), in both mesencephalic and striatal neurons, thereby effectively preventing dopaminergic neuron loss in vitro $[27,62]$. In another study, it was shown that fibroblast growth factor-2 expression is robustly induced in cultured astrocytes in response to R-apomorphine [26]. It is worth noting that the study was performed on cultured astrocytes derived from newborn animals, while the astrocytes from aged brains of Parkinson's disease may react differently in vitro. The aforementioned findings were not confirmed by our gene expression studies. Furthermore, if astrocytes in vivo will respond to R-apo- 
morphine treatment in the same way as reported in the aforementioned study needs to be investigated, as in vitro and in vivo findings do not always correlate.

The absence of sham lesioned rats within our experimental design may be considered by others as a study limitation. However, various publications indicate that sham lesioning of rodents has no effect on the main pathological hallmarks of Parkinson's disease, such as DA loss [30,37,43,63,64]. Furthermore, $\mathrm{Na}$ et al. [37] assessed the number of gene expression changes in vehicle and 6-OHDA lesioned striatum and substantia nigra at various time points by using cDNA microarray. They found that three days after vehicle administration there are profound changes in relative striatal gene expression levels ( $<50$ genes). However, this gene expression pattern began to wane as a function of time, and fourteen days after vehicle administration, the number of altered genes was almost equal to zero. A similar pattern was observed for 6-OHDA striatally lesioned rats. However, within this group the number of altered genes was much higher after 3 days ( $>150$ genes) and after 14 days ( $>50$ genes) compared to the vehicle lesioned rats. These findings suggest that sham lesioning has an effect on mRNA expression, but that it disappears very quickly as a function of time [37]. In addition, needle insertion and vehicle injection does not alter functional protein levels of BDNF and CNTF $[63,65]$. However, some astrocytic reaction in the neostriatum of solvent injected rats close to the needle track has been observed, while in the neurotoxin lesioned animals this reaction was much more widespread [66-68]. Our own findings also show that neurodegeneration caused by a unilateral injection of 6-OHDA in the medial forebrain bundle or the striatum, has no effect on the striatal protein expression of GDNF at different time points after lesion in the intact and the denervated striata of the lesioned animals and that of control animals [60]. The aforementioned findings suggest that the insertion of the needle for lesioning does not cause significant alterations in terms of striatal neurotransmitters and behaviour. However, some acute, minor and temporary effects have been observed at the gene and protein level, but this is limited to the needle tract. In our study, we assessed the gene and protein expression fourteen days after surgery. Even though, there would be an effect of the needle insertion, the combination with the neurotoxin is much more invasive and destructive.

Similarly, we did not include intact rats which have been treated with R-apomorphine, as we wanted to investigate the effects of R-apomorphine in the striatum of diseased, parkinsonian animals. Previously, we have shown that intact rats treated with R-apomorphine do not have any significant differences in striatal DA and DOPAC content, and DA turnover when compared to intact rats that didn't receive any treatment [14]. Furthermore, the number of tyrosine hydroxylase immunoreactive neurons in the $\mathrm{SNpc}$ were not different between intact rats and intact rats treated with $\mathrm{R}$-apomorphine.

\section{Conclusion}

Our data confirm the neuroprotective effects of R-apomorphine in the unilateral striatal 6-OHDA parkinsonian rat model and suggest that they involve the alteration of the striatal gene and the protein expression levels of the anti-inflammatory CRHR1 receptor and the pro-inflammatory CRHR2 receptor. Furthermore, treatment with Rapomorphine led to an upregulation of the NPY1R and NPY2R at the mRNA level. These results provide a better insight for understanding our previously observed neuroprotective effects of R-apomorphine in the unilateral striatal 6-OHDA parkinsonian rat model and confirm its potential anti-inflammatory action. However, additional investigations, e.g. functional studies, are required in order to confirm these findings. Despite the value of the 6-OHDA rat model, as illustrated in this work, one should be aware that the mechanism of 6-OHDA probably only reflects a small fraction of the events occurring in human Parkinson's disease. 6-OHDA induces rather acute effects, which differ significantly from the slowly progressive pathology of human Parkinson's disease. Moreover, Lewy body pathology is not present in the surviving neurons, and no other brain areas involved in Parkinson's disease are affected, such as the olfactory bulb and the locus coeruleus [69-71]. Therefore, further work would be valuable in understanding the potential therapeutic value of targeting the CRH and NPY recaptors in Parkinson's disease.

\section{Acknowledgements}

The authors wish to acknowledge the animal care by Mrs M. Cresens and technical assistance of Mrs. P. Verdood, Mr. E. Questier, Mr. S. Branson, Mrs R. Berckmans, Mr G. De Smet, Mrs C. De Rijck, and Mrs R.-M. Geens. We also thank Prof. Dr. Pharm. V. Rogiers, Prof. Dr. H. Heimberg and Prof. Dr. R Kooijman for the use of their laboratory facilities. This work was conducted with financial support of the Institute for the promotion of Innovation by Science and Technology in Flanders (IWT) (IWT420), National Fund for Scientific Research (FWOVlaanderen) (G.0071.05) and of the Research Council of the Vrije Universiteit Brussel. M. Varçin is holder of a research grant from the IWT (IWT420). E. Bentea is a research fellow of the FWO Vlaanderen.

\section{REFERENCES}

[1] A. H. Schapira, "Neurobiology and Treatment of Parkin- 
son's Disease," Trends in Pharmacological Sciences, Vol. 30, No. 1, 2009, pp. 41-47. http://dx.doi.org/10.1016/i.tips.2008.10.005

[2] M. B. Youdim, W. J. Geldenhuys and C. J. Van der Schyf, "Why Should We Use Multifunctional Neuroprotective and Neurorestorative Drugs for Parkinson's Disease?" Parkinsonism \& Related Disorders, Vol. 13, No. Suppl 3, 2007, pp. S281-S291. http://dx.doi.org/10.1016/S1353-8020(08)70017-8

[3] P. A. LeWitt, "Subcutaneously Administered Apomorphine: Pharmacokinetics and Metabolism," Neurology, Vol. 62, No. 6, 2004, pp. S8-S11.

http://dx.doi.org/10.1212/WNL.62.6 suppl 4.S8

[4] I. U. Haq, P. A. Lewitt and H. H. Fernandez, "Apomorphine Therapy in Parkinson's Disease: A Review," Expert Opinion on Pharmacotherapy, Vol. 8, No. 16, 2007, pp. 2799-2809.

http://dx.doi.org/10.1517/14656566.8.16.2799

[5] P. A. LeWitt, et al., "Open-Label Study Assessment of Safety and Adverse Effects of Subcutaneous Apomorphine Injections in Treating 'off' Episodes in Advanced Parkinson Disease," Clinical Neuropharmacology, Vol. 32, No. 2, 2009, pp. 89-93. http://dx.doi.org/10.1097/WNF.0b013e31816d91f9

[6] F. Stocchi, "Use of Apomorphine in Parkinson's Disease," Neurological Sciences, Vol. 29, No. Suppl 5, 2008, pp. S383-S386. http://dx.doi.org/10.1007/s10072-008-1053-8

[7] M. Kyriazis, "Neuroprotective, Anti-Apoptotic Effects of Apomorphine," Journal of Anti-Aging Medicine, Vol. 6, No. 1, 2003, pp. 21-28. http://dx.doi.org/10.1089/109454503765361551

[8] S. Ribaric, "The Pharmacological Properties and Therapeutic Use of Apomorphine," Molecules, Vol. 17, No. 5, 2012, pp. 5289-5309. http://dx.doi.org/10.3390/molecules17055289

[9] E. Grunblatt, et al., "Gene Expression Analysis in Nmethyl-4-phenyl-1,2,3,6-tetrahydropyridine Mice Model of Parkinson's Disease Using cDNA Microarray: Effect of R-Apomorphine," Journal of Neurochemistry, Vol. 78, No. 1, 2001, pp. 1-12.

http://dx.doi.org/10.1046/j.1471-4159.2001.00397.x

[10] E. Grunblatt, et al., “Apomorphine Protects against MPTPInduced Neurotoxicity in Mice," Movement Disorders, Vol. 14, No. 4, 1999, pp. 612-618.

http://dx.doi.org/10.1002/1531-8257(199907)14:4<612:: AID-MDS1010>3.0.CO;2-6

[11] G. Battaglia, et al., "Continuous Subcutaneous Infusion of Apomorphine Rescues Nigro-Striatal Dopaminergic Terminals Following MPTP Injection in Mice," Neuropharmacology, Vol. 42, No. 3, 2002, pp. 367-373. http://dx.doi.org/10.1016/S0028-3908(01)00178-2

[12] G. Battaglia, et al., "Morphological and Biochemical Evidence That Apomorphine Rescues Striatal Dopamine Terminals and Prevents Methamphetamine Toxicity," Annals of the New York Academy of Sciences, Vol. 965, 2002, pp. 254-266.

http://dx.doi.org/10.1111/j.1749-6632.2002.tb04167.x
[13] E. E. Sam and N. Verbeke, "Free Radical Scavenging Properties of Apomorphine Enantiomers and Dopamine: Possible Implication in Their Mechanism of Action in Parkinsonism," Journal of Neural Transmission Parkinson's Disease and Dementia Section, Vol. 10, No. 2-3, 1995, pp. 115-27. http://dx.doi.org/10.1007/BF02251227

[14] H. Yuan, et al., "Neuroprotective and Neurotrophic Effect of Apomorphine in the Striatal 6-OHDA-Lesion Rat Model of Parkinson's Disease," Brain Research, Vol. 1026, No. 1, 2004, pp. 95-107. http://dx.doi.org/10.1016/j.brainres.2004.08.015

[15] Y. K. Chen, et al., "Potent, Hydroxyl Radical-Scavenging Effect of Apomorphine with Iron and Dopamine Perfusion in Rat Striatum," Brain Research, Vol. 896, No. 1-2, 2001, pp. 165-168. http://dx.doi.org/10.1016/S0006-8993(01)02081-9

[16] F. Fornai, et al., "Dose-Dependent Protective Effects of Apomorphine against Methamphetamine-Induced Nigrostriatal Damage," Brain Research, Vol. 898, No. 1, 2001, pp. 27-35. http://dx.doi.org/10.1016/S0006-8993(01)02125-4

[17] E. Himeno, et al., "Apomorphine Treatment in Alzheimer Mice Promoting Amyloid-Beta Degradation," Annals of Neurology, Vol. 69, No. 2, 2011, pp. 248-256. http://dx.doi.org/10.1002/ana.22319

[18] M. Gassen, et al., "Apomorphine Is a Highly Potent Free Radical Scavenger in Rat Brain Mitochondrial Fraction," European Journal of Pharmacology, Vol. 308, No. 2, 1996, pp. 219-225. http://dx.doi.org/10.1016/0014-2999(96)00291-9

[19] G. Williamson, K. Faulkner and G. W. Plumb, "Glucosinolates and Phenolics as Antioxidants from Plant Foods," European Journal of Cancer Prevention, Vol. 7, No. 1, 1998, pp. 17-21.

[20] A. Ubeda, et al., "Iron-Reducing and Free-RadicalScavenging Properties of Apomorphine and Some Related Benzylisoquinolines," Free Radical Biology \& Medicine, Vol. 15, No. 2, 1993, pp. 159-167. http://dx.doi.org/10.1016/0891-5849(93)90055-Y

[21] H. Hara, M. Ohta and T. Adachi, "Apomorphine Protects against 6-Hydroxydopamine-Induced Neuronal Cell Death through Activation of the Nrf2-ARE Pathway," Journal of Neuroscience Research, Vol. 84, No. 4, 2006, pp. 860-866. http://dx.doi.org/10.1002/jnr.20974

[22] E. Grunblatt, et al., "Effects of R- and S-Apomorphine on MPTP-Induced Nigro-Striatal Dopamine Neuronal Loss,' Journal of Neurochemistry, Vol. 77, No. 1, 2001, pp. 146-156 http://dx.doi.org/10.1046/j.1471-4159.2001.t01-1-00227. $\underline{\mathrm{x}}$

[23] L. Ma, et al., "Activation of Glutathione Peroxidase and Inhibition of p53-Related Apoptosis by Apomorphine," Journal of Alzheimer's Disease, Vol. 27, No. 1, 2011, pp. 225-237.

[24] O. Weinreb, S. Mandel and M. B. Youdim, "Gene and Protein Expression Profiles of Anti- and Pro-Apoptotic Actions of Dopamine, R-Apomorphine, Green Tea Polyphenol (-)-Epigallocatechine-3-Gallate, and Melatonin," 
Annals of the New York Academy of Sciences, Vol. 993, No., 2003, pp. 351-361; Discussion 387-393. http://dx.doi.org/10.1111/j.1749-6632.2003.tb07544.x

[25] V. Coronas, et al., "Dopamine D3 Receptor Stimulation Promotes the Proliferation of Cells Derived from the Post-Natal Subventricular Zone," Journal of Neurochemistry, Vol. 91, No. 6, 2004, pp. 1292-1301. http://dx.doi.org/10.1111/j.1471-4159.2004.02823.x

[26] A. Li, et al., "Apomorphine-Induced Activation of Dopamine Receptors Modulates FGF-2 Expression in Astrocytic Cultures and Promotes Survival of Dopaminergic Neurons," FASEB Journal, Vol. 20, No. 8, 2006, pp. 1263-1265. http://dx.doi.org/10.1096/fj.05-5510fje

[27] H. Guo, et al., "Apomorphine Induces Trophic Factors That Support Fetal Rat Mesencephalic Dopaminergic Neurons in Cultures," European Journal of Neuroscience, Vol. 16, No. 10, 2002, pp. 1861-1870. http://dx.doi.org/10.1046/j.1460-9568.2002.02256.x

[28] M. Roceri, et al., "Stimulatory Role of Dopamine on Fibroblast Growth Factor-2 Expression in Rat Striatum," Journal of Neurochemistry, Vol. 76, No. 4, 2001, pp. 990-997. http://dx.doi.org/10.1046/j.1471-4159.2001.00088.x

[29] F. Vaglini, et al., "Apomorphine Offers New Insight into Dopaminergic Neuron Vulnerability in Mesencephalic Cultures," Neuropharmacology, Vol. 55, No. 5, 2008, pp. 737-742. http://dx.doi.org/10.1016/i.neuropharm.2008.06.041

[30] M. Varcin, et al., "Acute versus Long-Term Effects of 6Hydroxydopamine on Oxidative Stress and Dopamine Depletion in the Striatum of Mice," Journal Of Neuroscience Methods, Vol. 202, No. 2, 2011, pp. 128-136. http://dx.doi.org/10.1016/j.jneumeth.2011.07.004

[31] S. Taylor, et al., "A Practical Approach to RT-qPCRPublishing Data That Conform to the MIQE Guidelines," Methods, Vol. 50, No. 4, 2010, pp. S1-S5. http://dx.doi.org/10.1016/j.ymeth.2010.01.005

[32] G. Paxinos and C. Watson, "The Rat Brain in Stereotaxic Coordinates," 2nd Edition, Academic Press, Waltham, 1986.

[33] M. J. Millan, et al., "The Role of Dopamine D3 Compared with D2 Receptors in the Control of Locomotor Activity: A Combined Behavioural and Neurochemical Analysis with Novel, Selective Antagonists in Rats," Psychopharmacology (Berlin), Vol. 174, No. 3, 2004, pp. 341357. http://dx.doi.org/10.1007/s00213-003-1770-x

[34] B. Winner, et al., "Dopamine Receptor Activation Promotes Adult Neurogenesis in an Acute Parkinson Model," Experimental Neurology, Vol. 219, No. 2, 2009, pp. 543552. http://dx.doi.org/10.1016/j.expneurol.2009.07.013

[35] S. Mandel, O. Weinreb and M. B. Youdim, "Using cDNA Microarray to Assess Parkinson's Disease Models and the Effects of Neuroprotective Drugs," Trends in Pharmacological Sciences, Vol. 24, No. 4, 2003, pp. 184-191. http://dx.doi.org/10.1016/S0165-6147(03)00067-1

[36] A. S. Adewale, H. Macarthur and T. C. Westfall, "Neuropeptide Y Induced Modulation of Dopamine Synthesis in the Striatum," Regulatory Peptides, Vol. 129, No. 1-3, 2005, pp. 73-78. http://dx.doi.org/10.1016/j.regpep.2005.01.005

[37] S. J. Na, A. G. DiLella, E. V. Lis, K. Jones, D. M. Levine, D. J. Stone and J. F. Hess, "Molecular Profiling of a 6Hydroxydopamine Model of Parkinson's Disease," Neurochemical Research, Vol. 35, No. 5, 2010, pp. 761-772. http://dx.doi.org/10.1007/s11064-010-0133-3

[38] L. Marinova-Mutafchieva, M. Sadeghian, L. Broom, J. B. Davis, A. D. Medhurst and D. T. Dexter, "Relationship between Microglial Activation and Dopaminergic Neuronal Loss in the Substantia Nigra: A Time Course Study in a 6-Hydroxydopamine Model of Parkinson's Disease," Journal of Neurochemistry, Vol. 110, No. 3, 2009, pp. 966-975.

http://dx.doi.org/10.1111/j.1471-4159.2009.06189.x

[39] S. Walsh, D. P. Finn and E. Dowd, "Time-Course of Nigrostriatal Neurodegeneration and Neuroinflammation in the 6-Hydroxydopamine-Induced Axonal and Terminal Lesion Models of Parkinson's Disease in the Rat," Neuroscience, Vol. 175, 2009, pp. 251-261. http://dx.doi.org/10.1016/j.neuroscience.2010.12.005

[40] L. M. Collins, A. Toulouse, T. J. Connor and Y. M. Nolan, "Contributions of Central and Systemic Inflammation to the Pathophysiology of Parkinson's Disease," Neuropharmacology, Vol. 62, No. 7, 2012, pp. 2154-2168. http://dx.doi.org/10.1016/j.neuropharm.2012.01.028

[41] V. A. Doze and D. M. Perez, "G-Protein-Coupled Receptors in Adult Neurogenesis," Pharmacological Reviews, Vol. 64, No. 3, 2012, pp. 645-675. http://dx.doi.org/10.1124/pr.111.004762

[42] J. Ock, H. Lee, S. Kim, W. H. Lee, D. K. Choi, E. J. Park, S. H. Kim, I. K. Kim and K. Suk, "Induction of Microglial Apoptosis by Corticotropin-Releasing Hormone," Journal of Neurochemistry, Vol. 98, No. 3, 2006, pp. 962-972. http://dx.doi.org/10.1111/j.1471-4159.2006.03933.x

[43] A. Abuirmeileh, A. Harkavyi, A. Kingsbury, R. Lever and P. S. Whitton, "The CRF-Like Peptide Urocortin Greatly Attenuates Loss of Extracellular Striatal Dopamine in Rat Models of Parkinson's Disease by Activating CRF(1) Receptors," European Journal of Pharmacology, Vol. 604, No. 1-3, 2009, pp. 45-50. http://dx.doi.org/10.1016/j.ejphar.2008.11.009

[44] A. Abuirmeileh, A. Harkavyi, R. Lever, C. S. Biggs and P. S. Whitton, "Urocortin, a CRF-Like Peptide, Restores Key Indicators of Damage in the Substantia Nigra in a Neuroinflammatory Model of Parkinson's Disease," Journal of Neuroinflammation, Vol. 4, 2007, p. 19.

http://dx.doi.org/10.1186/1742-2094-4-19

[45] A. Abuirmeileh, R. Lever, A. E. Kingsbury, A. J. Lees, I. C. Locke, R. A. Knight, H. S. Chowdrey, C. S. Biggs and P. S. Whitton, "The Corticotrophin-Releasing Factor-Like Peptide Urocortin Reverses Key Deficits in Two Rodent Models of Parkinson's Disease," European Journal of Neuroscience, Vol. 26, No. 2, 2007, pp. 417-423. http://dx.doi.org/10.1111/j.1460-9568.2007.05653.x

[46] W. A. Pedersen, R. Wan, P. Zhang and M. P. Mattson, "Urocortin, but not Urocortin II, Protects Cultured Hip- 
pocampal Neurons from Oxidative and Excitotoxic Cell Death via Corticotropin-Releasing Hormone Receptor Type I," Journal of Neuroscience, Vol. 22, No. 2, 2002, pp. 404412.

[47] E. Gonzalez-Rey, A. Fernandez-Martin, A. Chorny and M. Delgado, "Therapeutic Effect of Urocortin and Adrenomedullin in a Murine Model of Crohn's Disease," Gut, Vol. 55, No. 6, 2006, pp. 824-832.

http://dx.doi.org/10.1136/gut.2005.084525

[48] H. Y. Huang, S. Z. Lin, W. F. Chen, K. W. Li, J. S. Kuo and M. J. Wang, "Urocortin Modulates Dopaminergic Neuronal Survival via Inhibition of Glycogen Synthase Kinase$3 \beta$ and Histone Deacetylase," Neurobiology of Aging, Vol. 32, No. 9, 2011, pp. 1662-1677. http://dx.doi.org/10.1016/j.neurobiolaging.2009.09.010

[49] Y. Kim, M. K. Park and S. Chung, "Protective Effect of Urocortin on 1-Methyl-4-Phenylpyridinium-Induced Dopaminergic Neuronal Death," Molecules and Cells, Vol. 30, No. 5, 2010, pp. 427-433. http://dx.doi.org/10.1007/s10059-010-0132-x

[50] A. C. Moss, P. Anton, T. Savidge, et al., "Urocortin II Mediates Pro-Inflammatory Effects in Human Colonocytes via Corticotropin-Releasing Hormone Receptor $2 \alpha$," Gut, Vol. 56, No. 9, 2007, pp. 1210-1217. http://dx.doi.org/10.1136/gut.2006.110668

[51] E. Kokkotou, D. Torres, A. C. Moss, M. O'Brien, D. E. Grigoriadis, K. Karalis and C. Pothoulakis, "CorticotropinReleasing Hormone Receptor 2-Deficient Mice Have Reduced Intestinal Inflammatory Responses," Journal of Immunology, Vol. 177, No. 5, 2006, pp. 3355-3361.

[52] M. Decressac, L. Prestoz, J. Veran, A. Cantereau, M. Jaber and A. Gaillard, "Neuropeptide Y Stimulates Proliferation, Migration and Differentiation of Neural Precursors from the Subventricular Zone in Adult Mice," Neurobiology of Disease, Vol. 34, No. 3, 2009, pp. 441-449. http://dx.doi.org/10.1016/j.nbd.2009.02.017

[53] M. Dimitrijevic, S. Stanojevića, K. Mitića, N. Kuštrimovića, V. Vujićb, T. Miletića and V. Kovačević-Jovanovića, "The Anti-Inflammatory Effect of Neuropeptide Y (NPY) in Rats Is Dependent on Dipeptidyl Peptidase 4 (DP4) Activity and Age," Peptides, Vol. 29, No. 12, 2008, pp. 2179-2187. http://dx.doi.org/10.1016/j.peptides.2008.08.017

[54] M. Decressac, B. Wright, B. David, P. Tyers, M. Jaber, R. A. Barker and A. Gaillard, "Exogenous Neuropeptide Y Promotes in Vivo Hippocampal Neurogenesis," Hippocampus, Vol. 21, No. 3, 2011, pp. 233-238. http://dx.doi.org/10.1002/hipo.20765

[55] N. Thiriet, X. L. Deng, M. Solinas, B. Ladenheim, W. Curtis, S. R. Goldberg, R. D. Palmiter and J. L. Cadet, "Neuropeptide Y Protects against Methamphetamine-Induced Neuronal Apoptosis in the Mouse Striatum," Journal of Neuroscience, Vol. 25, No. 22 , 2005, pp. 52735279.

http://dx.doi.org/10.1523/JNEUROSCI.4893-04.2005

[56] A. S. Adewale, H. Macarthur and T. C. Westfall, "Neuropeptide Y-Induced Enhancement of the Evoked Release of Newly Synthesized Dopamine in Rat Striatum: Mediation by Y2 Receptors," Neuropharmacology, Vol. 52, No.
6, 2007, pp. 1396-1402.

http://dx.doi.org/10.1016/j.neuropharm.2007.01.018

[57] D. Quarta, C. P. Leslie, R. Carletti, E. Valerio and L. Caberlotto, "Central Administration of NPY or an NPY-Y5 Selective Agonist Increase in Vivo Extracellular Monoamine Levels in Mesocorticolimbic Projecting Areas," Neuropharmacology, Vol. 60, No. 2-3, 2011, pp. 328-335. http://dx.doi.org/10.1016/j.neuropharm.2010.09.016

[58] E. Zambello, L. Zanetti, G. F. Hédou, O. Angelici, R. Arban, R. O. Tasan, G. Sperk and L. Caberlotto, "Neuropeptide Y-Y2 Receptor knockout Mice: Influence of Genetic Background on Anxiety-Related Behaviors," Neuroscience, Vol. 176, No., 2010, pp. 420-430. http://dx.doi.org/10.1016/i.neuroscience.2010.10.075

[59] M. Smialowska, H. Domin, B. Zieba, E. Koźniewska, R. Michalik, P. Piotrowski and M. Kajta, "Neuroprotective Effects of Neuropeptide Y-Y2 and Y5 Receptor Agonists in Vitro and in Vivo," Neuropeptides, Vol. 43, No. 3, 2009, pp. 235-249. http://dx.doi.org/10.1016/j.npep.2009.02.002

[60] B. Mertens, A. Massie, Y. Michotte and S. Sarre, "Effect of Nigrostriatal Damage Induced by 6-Hydroxydopamine on the Expression of Glial Cell Line-Derived Neurotrophic Factor in the Striatum of the Rat," Neuroscience, Vol. 162, No. 1, 2009, pp. 148-154.

http://dx.doi.org/10.1016/j.neuroscience.2009.04.036

[61] S. Mandel, E. Grünblatt, P. Riederer and M. B. Youdim, "Genes and Oxidative Stress in Parkinsonism: cDNA Microarray Studies," Advances in Neurology, Vol. 91, 2003, pp. 123-132.

[62] M. Ohta, I. Mizuta, K. Ohta, M. Nishimura, E. Mizuta, K. Hayashid and S. Kuno, "Apomorphine Up-Regulates NGF and GDNF Synthesis in Cultured Mouse Astrocytes," Biochemical and Biophysical Research Communications, Vol. 272, No. 1, 2000, pp. 18-22. http://dx.doi.org/10.1006/bbrc.2000.2732

[63] I. Branchi, I. D’Andreaa, M. Armida, et al., "Striatal 6OHDA Lesion in Mice: Investigating Early Neurochemical Changes Underlying Parkinson's Disease," Behavioural Brain Research, Vol. 208, No. 1, 2010, pp. 137-143. http://dx.doi.org/10.1016/j.bbr.2009.11.020

[64] V. Francardo, A. Recchia, N. Popovic, D. Andersson, H. Nissbrandt and M. A. Cenci, "Impact of the Lesion Procedure on the Profiles of Motor Impairment and Molecular Responsiveness to L-DOPA in the 6-Hydroxydopamine Mouse Model of Parkinson's Disease," Neurobiology of Disease, Vol. 42, No. 3, 2011, pp. 327-340. http://dx.doi.org/10.1016/j.nbd.2011.01.024

[65] S. J. Haas, A. Ahrens, S. Petrov, O. Schmitt and A. Wree, "Quinolinic Acid Lesions of the Caudate Putamen in the Rat Lead to a Local Increase of Ciliary Neurotrophic Factor," Journal of Anatomy, Vol. 204, No. 4, 2004, pp. 271281. http://dx.doi.org/10.1111/j.0021-8782.2004.00279.x

[66] R. W. Rodrigues, V. C. Gomide and G. Chadi, "Astroglial and Microglial Activation in the Wistar Rat Ventral Tegmental Area after a Single Striatal Injection of 6-Hydroxydopamine," International Journal of Neuroscience, Vol. 114, No. 2, 2004, pp. 197-216. 
http://dx.doi.org/10.1080/00207450490249338

[67] V. C. Gomide, G. A. Silveira and G. Chadi, "Transient and Widespread Astroglial Activation in the Brain after a Striatal 6-OHDA-Induced Partial Lesion of the Nigrostriatal System," International Journal of Neuroscience, Vol. 115, No. 1, 2005, pp. 99-117. http://dx.doi.org/10.1080/00207450490512696

[68] J. Henning, U. Strauss, A. Wree, J. Gimsa, A. Rolfs, R. Benecke and U. Gimsa, "Differential Astroglial Activation in 6-Hydroxydopamine Models of Parkinson's Disease," Neuroscience Research, Vol. 62, No. 4, 2008, pp. 246253. http://dx.doi.org/10.1016/j.neures.2008.09.001

[69] M. E. Emborg, "Evaluation of Animal Models of Parkin- son's Disease for Neuroprotective Strategies," Journal of Neuroscience Methods, Vol. 139, No. 2, 2004, pp. 121143. http://dx.doi.org/10.1016/j.jneumeth.2004.08.004

[70] F. Blandini, M. T. Armentero and E. Martignoni, "The 6-Hydroxydopamine Model: News from the Past," Parkinsonism \& Related Disorders, Vol. 14, Suppl. 2, 2008, pp. S124-S129. http://dx.doi.org/10.1016/j.parkreldis.2008.04.015

[71] S. Duty and P. Jenner, “Animal Models of Parkinson's Disease: A Source of Novel Treatments and Clues to the Cause of the Disease," British Journal of Pharmacology, Vol. 164, No. 4, 2011, pp. 1357-1391. http://dx.doi.org/10.1111/j.1476-5381.2011.01426.x 